\title{
Putting the Squeeze on Molecule-Based Magnets: Exploiting Pressure to Develop Magneto-Structural Correlations in Paramagnetic Coordination Compounds
}

\author{
Alvaro Etcheverry-Berrios ${ }^{1}$ (D), Simon Parsons ${ }^{1, *}$, Konstantin V. Kamenev ${ }^{2, *}$, \\ Michael R. Probert ${ }^{3, *}$, Stephen A. Moggach ${ }^{4, *}$, Mark Murrie ${ }^{5, *}$ and Euan K. Brechin $1, *$ (D) \\ 1 EaStCHEM School of Chemistry and Centre for Science at Extreme Conditions, The University of Edinburgh, \\ David Brewster Road, Edinburgh EH9 3FJ, UK; alvaro.et@ed.ac.uk \\ 2 School of Engineering and Centre for Science at Extreme Conditions, The University of Edinburgh, \\ Peter Guthrie Tait Road, Edinburgh EH9 3FD, UK \\ 3 School of Natural and Environmental Sciences, Newcastle University, Kings Road, Newcastle NE1 7RU, UK \\ 4 School of Molecular Sciences and Centre for Microscopy, Characterisation and Analysis, University of \\ Western Australia, 35 Stirling Highway, Crawley, Perth 6005, Australia \\ 5 School of Chemistry, University of Glasgow, University Avenue, Glasgow G12 8QQ, UK \\ * Correspondence: Simon.Parsons@ed.ac.uk (S.P.); K.Kamenev@ed.ac.uk (K.V.K.); \\ michael.probert@ncl.ac.uk (M.R.P.); stephen.moggach@uwa.edu.au (S.A.M.); \\ Mark.Murrie@glasgow.ac.uk (M.M.); ebrechin@ed.ac.uk (E.K.B.)
}

Received: 20 July 2020; Accepted: 10 August 2020; Published: 12 August 2020

\begin{abstract}
The cornerstone of molecular magnetism is a detailed understanding of the relationship between structure and magnetic behaviour, i.e., the development of magneto-structural correlations. Traditionally, the synthetic chemist approaches this challenge by making multiple compounds that share a similar magnetic core but differ in peripheral ligation. Changes in the ligand framework induce changes in the bond angles and distances around the metal ions, which are manifested in changes to magnetic susceptibility and magnetisation data. This approach requires the synthesis of a series of different ligands and assumes that the chemical/electronic nature of the ligands and their coordination to the metal, the nature and number of counter ions and how they are positioned in the crystal lattice, and the molecular and crystallographic symmetry have no effect on the measured magnetic properties. In short, the assumption is that everything outwith the magnetic core is inconsequential, which is a huge oversimplification. The ideal scenario would be to have the same complex available in multiple structural conformations, and this is something that can be achieved through the application of external hydrostatic pressure, correlating structural changes observed through high-pressure single crystal X-ray crystallography with changes observed in high-pressure magnetometry, in tandem with high-pressure inelastic neutron scattering (INS), high-pressure electron paramagnetic resonance (EPR) spectroscopy, and high-pressure absorption/emission/Raman spectroscopy. In this review, which summarises our work in this area over the last 15 years, we show that the application of pressure to molecule-based magnets can (reversibly) (1) lead to changes in bond angles, distances, and Jahn-Teller orientations; (2) break and form bonds; (3) induce polymerisation/depolymerisation; (4) enforce multiple phase transitions; (5) instigate piezochromism; (6) change the magnitude and sign of pairwise exchange interactions and magnetic anisotropy, and (7) lead to significant increases in magnetic ordering temperatures.
\end{abstract}

Keywords: high pressure X-ray crystallography; high pressure magnetometry; high pressure absorption spectroscopy; molecule-based magnets; single-molecule magnets; single-ion magnets 


\section{Introduction}

Over the last 50 years, there has been a significant increase in the number of high-pressure single-crystal and powder diffraction studies performed on molecular systems, with several comprehensive reviews on the subject, including the effect of pressure on amino acids [1], metal complexes [2] and metal-organic frameworks [3,4]. The complexity of molecular systems examined under pressure has grown significantly with the first molecules consisting of just a handful of atoms, such as benzene, which was first published in 1969 [5]. More recently, molecular porous systems containing thousands of atoms and with unit cell volumes in excess of 55,000 $\AA^{3}$ have been studied (Figure 1) [6]. In all, some 3328 structures in the Cambridge Structural Database (CSD) have been collected at pressure to date (CSD version 5.41).

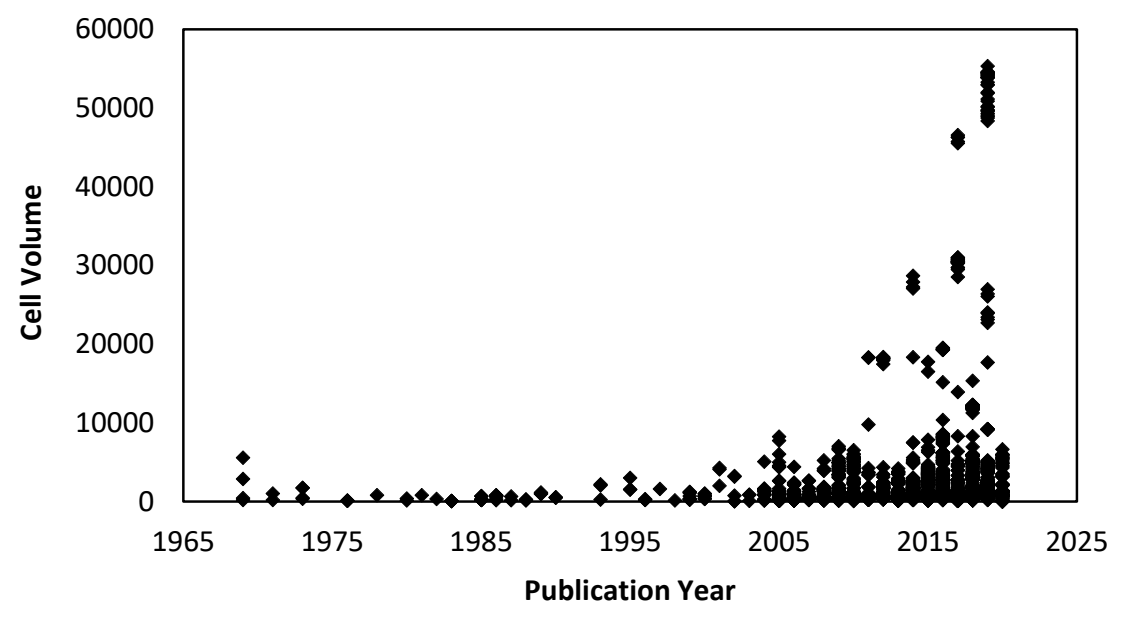

Figure 1. Cell volume versus publication year for all high-pressure structures collected in the Cambridge Structural Database (CSD) (version 5.41) that contain the required field 'pressure' in the cif.

Advances in pressure cell technology, and in particular the size and ease of use of diamond anvil cells (DACs) such as the Merrill Bassett cell [7], turnbuckle cell [8], and other miniature diamond anvil cells [9] has made possible the study of molecular systems of increasing complexity. One area where the use of pressure has seen a significant rise in popularity is in the study of functional materials where high-pressure diffraction studies performed in conjunction with other high-pressure measurements on the same sample have helped develop structure-property relationships. Supplementary techniques have included high-pressure UV-Vis [10], fluorescence emission [11], conductivity [12], Mössbauer [13], and magnetic measurements. These combined studies have revealed how structural distortions, caused by increasing pressure, have enforced changes in the physical properties of materials. Examples include measuring changes in conductivity and band structure in molecular conductors [12], monitoring framework 'breathing effects' on the uptake of guest species within porous metal-organic framework materials [14], and how structural changes in encapsulated fluorophores affect emission properties [11]. One area where this approach has made a significant impact is in the field of magnetism. Herein, we highlight our efforts in developing magneto-structural correlations in transition metal molecule-based magnets; we do not attempt to cover examples from other researchers, which are many and varied [15-31]. At the outset, what we hoped to observe was that applied pressure would change bond lengths and angles around the metal centres, and that that would lead to changes in magnetic exchange interactions and/or magneto-anisotropies. Our reasons for choosing particular complexes to study were, at least initially, influenced by those whose ambient structure-property relations had been well established in the literature. Some came from our own back catalogue of compounds, the structures and physical properties of which we understood well. All exchange interactions $(J)$ in this review are quoted in the $H=\Sigma-2 J_{\mathrm{ij}} S_{\mathrm{i}} S_{\mathrm{j}}$ formalism. 


\section{Mn Complexes}

The compounds we chose to study first were those containing $\mathrm{Mn}^{\mathrm{III}}$. This was for a number of reasons. At the beginning of our combined research efforts in 2006, we were making $\mathrm{Mn}^{\mathrm{III}}$-based Single-Molecule Magnets (SMMs) and had a large library of complexes from which to choose, many of which had very interesting structural/magnetic features [32,33]. Aligned to this was the presence of the Jahn-Teller (JT) axis of the octahedral $\mathrm{Mn}^{\mathrm{III}}$ ion. Given the well-known dynamic JT effect observed in numerous coordination compounds [34], we speculated that hydrostatic pressure would be capable of changing JT bond lengths/orientations, and that that would have a pronounced effect on both magnetic exchange interactions and magnetic anisotropy.

The compounds $\left[\mathrm{Mn}_{6} \mathrm{O}_{2}(\mathrm{Et}-\mathrm{sao})_{6}\left(\mathrm{O}_{2} \mathrm{CPh}(\mathrm{Me})_{2}\right)_{2}(\mathrm{EtOH})_{6}\right]$ (1) and $\left[\mathrm{Mn}_{6} \mathrm{O}_{2}(\mathrm{Et}-\mathrm{sao})_{6}\left(\mathrm{O}_{2} \mathrm{C}-\right.\right.$ naphth $\left.)_{2}(\mathrm{EtOH})_{4}\left(\mathrm{H}_{2} \mathrm{O}\right)_{2}\right]\left(2\right.$; sao $^{2-}$ is the dianion of salicylaldoxime) are part of a well-studied family of SMMs for which detailed magneto-structural correlations under ambient conditions have been developed [35-37]. The general structure of these complexes (Figure 2) describes two parallel, off-set $\left[\mathrm{Mn}_{3}{ }_{3}\left(\mu_{3}-\mathrm{O}\right)\right]^{7+}$ triangular subunits linked via two central oximate O-atoms and two peripheral phenoxide O-atoms, leading to a $\left[\mathrm{Mn}_{6}{ }_{6}\left(\mu_{3}-\mathrm{O}\right)_{2}\left(\mu_{3}-\mathrm{ONR}\right)_{2}(\mu-\mathrm{ONR})_{4}\right]^{8+}$ core. The bridging between neighbouring $\mathrm{Mn}$ ions within each triangle occurs through an $\mathrm{NO}$ oximate group, such that each $\mathrm{Mn}_{2}$ pair forms a $-\mathrm{Mn}-\mathrm{N}-\mathrm{O}-\mathrm{Mn}-$ moiety, and thus the $\mathrm{Mn}_{3}$ triangle, a $(-\mathrm{Mn}-\mathrm{O}-\mathrm{N}-)_{3}$ ring. The coordination spheres of the Mn ions are completed by two terminal carboxylates (one on each triangle) and by terminal solvent molecules. All $\mathrm{Mn}$ ions are in the $3+$ oxidation state and are six-coordinate adopting distorted (pseudo) octahedral geometry, with their axially elongated JT axes approximately perpendicular to the $\left[\mathrm{Mn}_{3} \mathrm{O}\right]^{7+}$ planes [38]. All family members can be categorised into two subsections according to their magnetic behaviour: those possessing intra-triangle antiferromagnetic exchange interactions, and those possessing intra-triangle ferromagnetic exchange interactions. All family members display inter-triangle ferromagnetic exchange. This results in compounds with $S=12$ ground states in the latter and $4 \leq S<12$ ground states in the former. Interestingly, the sign and magnitude of the magnetic exchange is controlled through $\mathrm{R}-\mathrm{saoH}_{2}$ ligand design, with larger, non-rigid $\mathrm{R}$ (in the main, e.g., $\mathrm{R}=\mathrm{Me}, \mathrm{Et}$ ) causing puckering of the $-\mathrm{Mn}-\mathrm{N}-\mathrm{O}-\mathrm{Mn}-$ moiety. The change in torsion angle from near planar (when $\mathrm{R}=\mathrm{H}$ for example) to non-planar decreases the antiferromagnetic contribution to the nearest-neighbour exchange, and at approximately $31^{\circ}$, the pairwise interaction switches to being ferromagnetic [39]. Given that such enormous changes in magnetic behaviour are observed through very small changes in structure, aligned to the fact that the magnitude of the exchange $(J)$ is very small (and thus the absolute difference in $J$ is small) made compounds $\mathbf{1}$ and $\mathbf{2}$ ideal candidates for the first ever combined HP single crystal $\mathrm{X}$-ray diffraction/HP magnetic study of a SMM.

a)

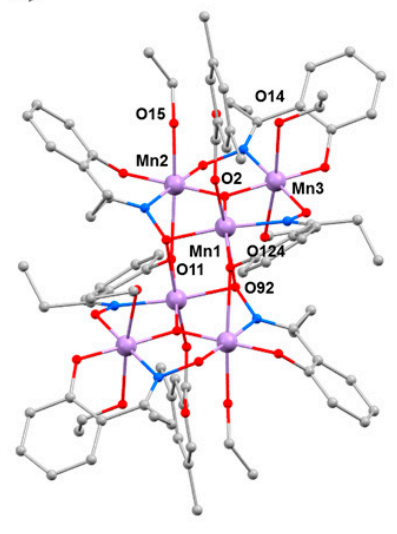

b)

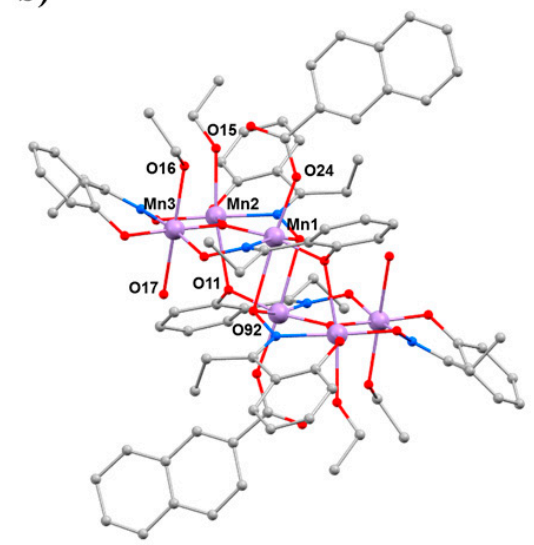

c)

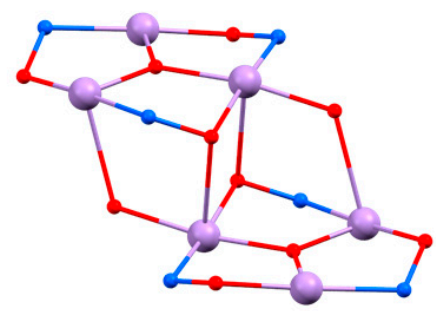

Figure 2. (a) The molecular structure of complex 1. (b) The molecular structure of complex 2. (c) The metallic skeleton common to $\mathbf{1}$ and 2. Colour code: $\mathrm{Mn}=$ lilac, $\mathrm{O}=$ red, $\mathrm{N}=$ blue, $\mathrm{C}=$ grey. $\mathrm{H}$ atoms are omitted for clarity. 
Hydrostatic high-pressure (HP) single-crystal X-ray diffraction (XRD) measurements were performed on 1 and 2 in petroleum ether at $T=300 \mathrm{~K}$ to a maximum pressure of $1.5 \mathrm{GPa}$ [40]. 1 and 2 crystallise in the monoclinic space groups $P 2_{1} / n$ and $P 2_{1} / c$, respectively, and remain so in the full pressure range. The most obvious initial effect for both is a compression of the unit cell, by approximately $6.5 \%(1)$ and $10 \%(2)$, which is assigned to a reduction of void space given the lack of significant intermolecular interactions (H-bonds or $\pi-\pi$ stacking). The closest intermolecular interactions $(\mathrm{H} \cdots \mathrm{H})$ reduce by a maximum of approximately $0.9 \AA$ in $\mathbf{1}$ and just $0.07 \AA$ in $\mathbf{2}$. The intramolecular changes are more remarkable (Figure 3), with the $\mathrm{Mn}-\mathrm{N}-\mathrm{O}-\mathrm{Mn}$ torsion angles flattened considerably, and the JT axes compressing and re-aligning differently with respect to the plane of the three metal centres in the triangle (Tables 1 and 2). The $\mathrm{Mn}-\mathrm{N}-\mathrm{O}-\mathrm{Mn}$ torsion angles decrease by up to approximately $5.1^{\circ}(\mathbf{1}), 5.7^{\circ}$ (2). Significantly, the Mn1-N-O-Mn3 torsion angle in both cases falls from above to below the angle expected to switch the pairwise exchange from ferromagnetic to antiferromagnetic; $34.8(5) \rightarrow 29.7(11)^{\circ}(\mathbf{1}), 33.2(2) \rightarrow 27.5(17)^{\circ}(\mathbf{2})$. Note that Mn3 lies at the periphery of the molecule, away from the more structurally rigid core, and it is the only metal ion bonded to two solvent molecules, which sit on its JT axis. The changes in the JT axes with pressure are less consistent. For $\mathbf{1}$, the JT axes of Mn1 and Mn2 are compressed with pressure (2.132(2), 2.434(3) $\AA \rightarrow$ 2.093(5), 2.359(5) $\AA$; 2.196(3), 2.480(3) $\AA \rightarrow 2.151(6), 2.423(7) \AA$, respectively). However, the JT of Mn3 actually elongates at $0.5 \mathrm{GPa}$, before compressing at all other (higher) pressures, resulting in a small overall compression of one bond and a small overall elongation of the other. All three JT axes move to become slightly more perpendicular to the mean plane of the $\left[\mathrm{Mn}_{3}\right]$ triangle, albeit by just approximately $0.9-1.6^{\circ}$. In 2, the JT axes all compress with pressure (Mn1, 2.102(3), 2.508(3) $\AA \rightarrow 2.033(7), 2.486(9) \AA ;$ Mn2, 2.205(3), 2.397(3) $\AA \rightarrow 2.141(9), 2.387(11) \AA$; Mn3, 2.395(3), 2.188(3) $\AA \rightarrow$ 2.398(7), 2.107(7) $\AA$ ) and variations in the alignment of the axes are within the statistical error, although the trend appears analogous to that seen for $\mathbf{1}$.
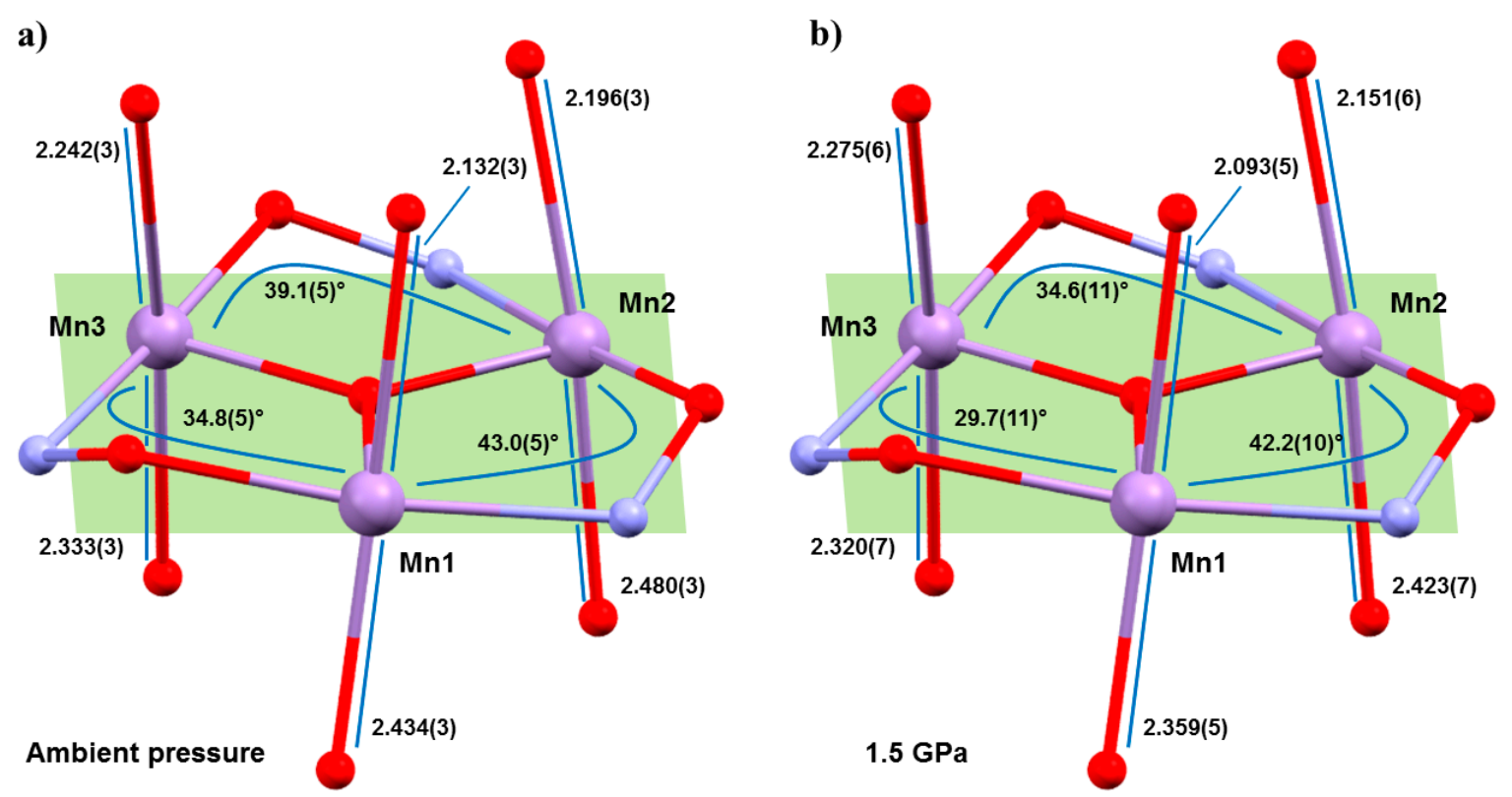

Figure 3. Comparison of Jahn-Teller bond lengths and $\mathrm{Mn}-\mathrm{O}-\mathrm{N}-\mathrm{Mn}$ torsion angles in $\mathbf{1}$ at (a) ambient pressure and (b) $1.5 \mathrm{GPa}$. Colour code as Figure 1. 
Table 1. Comparison of the Mn-O-N-Mn torsion angles $\left(^{\circ}\right)$ at ambient pressure and at $1.5 \mathrm{GPa}$ for complexes 1 and 2.

\begin{tabular}{ccccc}
\hline & $\begin{array}{c}\text { At Ambient } \\
\text { Pressure in 1 }\end{array}$ & $\begin{array}{c}\text { At 1.5 GPa } \\
\text { in 1 }\end{array}$ & $\begin{array}{c}\text { At Ambient } \\
\text { Pressure in 2 }\end{array}$ & $\begin{array}{c}\text { At 1.5 GPa } \\
\text { in 2 }\end{array}$ \\
\hline $\mathrm{Mn} 1-\mathrm{O}-\mathrm{N}-\mathrm{Mn} 2{ }^{\circ}$ & $43.0(2)$ & $42.2(10)$ & $41.1(2)$ & $41.1(1.7)$ \\
$\mathrm{Mn} 2-\mathrm{O}-\mathrm{N}-\mathrm{Mn} 3{ }^{\circ}$ & $39.1(2)$ & $34.6(11)$ & $40.5(2)$ & $36.5(1.8)$ \\
$\mathrm{Mn} 3-\mathrm{O}-\mathrm{N}-\mathrm{Mn} 1{ }^{\circ}$ & $34.8(5)$ & $29.7(11)$ & $33.2(2)$ & $27.5(1.7)$ \\
\hline
\end{tabular}

Table 2. Comparison of the bond lengths $(\AA)$ of the Jahn-Teller axes at ambient pressure and at $1.5 \mathrm{GPa}$ for complexes 1 and 2.

\begin{tabular}{|c|c|c|c|c|c|c|}
\hline & Mn1-O2/Å & Mn1-O92/Å & Mn2-O15/Å & Mn2-O11/Å & Mn3-O14/Å & Mn3-O124/Å \\
\hline At ambient pressure in $\mathbf{1}$ & $2.132(2)$ & 2.434(3) & $2.196(3)$ & $2.480(3)$ & $2.242(3)$ & 2.333(3) \\
\hline \multirow[t]{2}{*}{ At $1.5 \mathrm{GPa}$ in $\mathbf{1}$} & 2.093(5) & $2.359(5)$ & $2.151(6)$ & $2.423(7)$ & $2.275(6)$ & $2.320(7)$ \\
\hline & Mn1-O24/Å & Mn1-O92/Å & Mn2-O15/Å & Mn2-O11/Å & Mn3-O17/Å & Mn3-O16/Å \\
\hline At ambient pressure in 2 & 2.102(3) & $2.508(3)$ & $2.205(3)$ & 2.397(3) & 2.395(3) & $2.188(3)$ \\
\hline At $1.5 \mathrm{GPa}$ in 2 & $2.033(7)$ & $2.486(9)$ & $2.141(9)$ & $2.387(11)$ & $2.398(7)$ & $2.107(7)$ \\
\hline
\end{tabular}

HP susceptibility and magnetisation data were collected to 2 GPa using Daphne 7373 oil as the pressure transmitting medium. The magnetic behaviour of $\mathbf{1}$ and $\mathbf{2}$ at ambient pressure has been described in detail previously [32,41]. In the following text, the numbers in brackets refer to complex 2. Data measured in the cell, but with zero applied pressure $(T=300-5 \mathrm{~K}, B=0.1 \mathrm{~T})$, can be simulated with the parameters $g=1.99(2.03)$ and $J=+1.75(+1.31) \mathrm{cm}^{-1}$ in a model assuming all exchange interactions are the same. With increasing pressure, the value of $\chi_{\mathrm{M}} T$ increases more slowly with decreasing temperature and has a much smaller maximum for both complexes, which is clearly indicative of a weaker (less positive) ferromagnetic exchange interaction, and/or the presence of antiferromagnetic exchange. Indeed, simulation of the susceptibility data for $\mathbf{1}$ at the highest pressures measured requires the introduction of a $2 \mathrm{~J}$ model in which the Mn1-Mn3 exchange interaction is antiferromagnetic $\left(J_{1}=+1.10(+1.00) \mathrm{cm}^{-1}, J_{\mathrm{Mn} 1-3}=-0.10(-0.45) \mathrm{cm}^{-1}\right)$, which is consistent with the structural changes in the torsion angles. Simulations suggest the spin ground state remains $S=12$ at lower pressures, but it switches to $S=11$ (or smaller) at higher pressures. A fit of the magnetisation data for compound 1 measured in the cell, but with zero applied pressure $(T=2-7 \mathrm{~K}$, $B=0.5-5.0 \mathrm{~T}$ ) to an axial zero-field splitting $(z f s)$ plus Zeeman Hamiltonian (Giant Spin Model) affords $S=12, g=1.99$, and $D=-0.38 \mathrm{~cm}^{-1}$, which is consistent with that observed for all ferromagnetically coupled members of the family. At the highest pressures measured, these parameters become $S=11$, $g=1.98$, and $D=-0.34 \mathrm{~cm}^{-1}$. The data for 2 could not be fitted, but qualitatively show a similar trend in behaviour. As expected with decreasing $|J|$ and the introduction of antiferromagnetic exchange, the barrier to magnetisation reversal in these SMMs is reduced dramatically (Figure 4). There is a clear pressure and frequency-dependent decrease in the out-of-phase, $\chi_{\mathrm{M}}{ }^{\prime \prime}$, peak positions in the ac susceptibility data from $T \leq 6 \mathrm{~K}$. For example, for 1, the peak at $300 \mathrm{~Hz}$ at $0(1.75) \mathrm{GPa}$ occurs at approximately 6.3(4.8) K; for 2, the peak at $100 \mathrm{~Hz}$ at $0(1.4) \mathrm{GPa}$ occurs at 3.9(3.0) K. A fit of the HP $\chi_{\mathrm{M}}{ }^{\prime \prime}$ data to the Arrhenius equation revealed a decrease in $\underline{U}_{\text {eff }}$ in $\mathbf{1}(2)$ from $83(63) \mathrm{K}$ to $63(47) \mathrm{K}$. This is also manifested in the change in the appearance of the magnetisation hysteresis loops that show a clear reduction in coercivity with increased pressure (Figure 4). 
a)

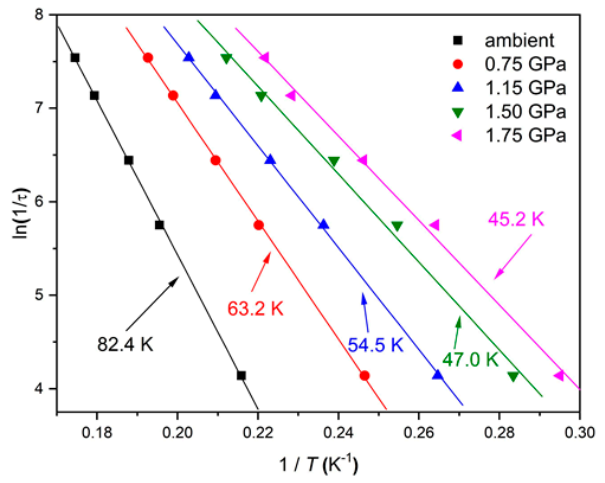

b)

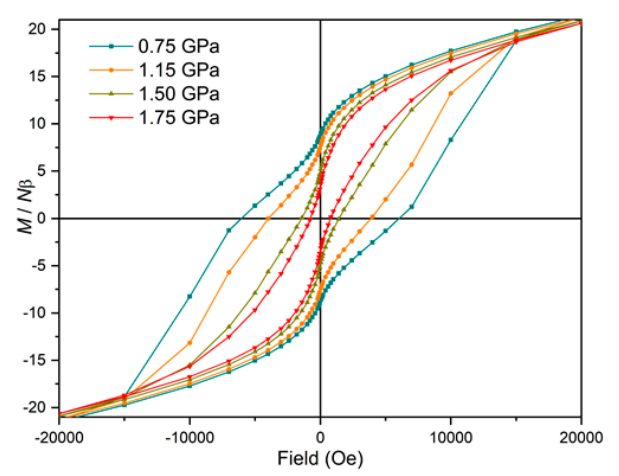

Figure 4. (a) Arrhenius plots based on out-of-phase ac susceptibility measurements of 1 at different pressures. (b) Hysteresis loops for 1 recorded at the indicated pressures at $2 \mathrm{~K}$.

The second SMM to be the focus of a combined HP crystallography/magnetism study was the compound $\left[\mathrm{Mn}_{3}(\mathrm{Hcht})_{2}(\mathrm{bpy})_{4}\right]\left(\mathrm{ClO}_{4}\right)_{3} \cdot \mathrm{Et}_{2} \mathrm{O} \cdot 2 \mathrm{MeCN}\left(3 \cdot \mathrm{Et}_{2} \mathrm{O} \cdot 2 \mathrm{MeCN} ; \mathrm{Hcht}^{2-}\right.$ is the dianion of cis,cis-1,3,5-cyclohexanetriol and bpy is 2,2'-bipyridine) [42,43]. The structure of 3 (Figure 5) contains a linear $\left[\mathrm{Mn}^{\mathrm{III}} \mathrm{Mn}_{2}{ }_{2} \mathrm{O}_{4}\right]^{3+}$ core with the central $\mathrm{Mn}^{\mathrm{III}}$ centre (Mn1) bound to the peripheral $\mathrm{Mn}^{\mathrm{II}}$ ions ( $\mathrm{Mn} 2$ and symmetry equivalent, s.e.) by four alkoxide O-atoms (O15 and s.e.) provided by two $\mathrm{Hcht}^{2-}$ ligands, which are positioned one above and one below the trimetallic chain. One protonated oxygen atom (O20 and s.e.) from the tripodal alcohol defines the JT axis of $\mathrm{Mn} 1$. The $\mathrm{Mn}{ }^{\mathrm{III}}-\mathrm{O}-\mathrm{Mn}^{\mathrm{II}}$ angle is approximately $102^{\circ}$, with the coordination sites of each $\mathrm{Mn}^{\mathrm{II}}$ ion completed by four $\mathrm{N}$-atoms from two 2,2'-bipyridine (bpy) ligands. Mn2 (and s.e) are in highly distorted octahedral geometries with cis angles in the range $72.30(16)-105.65(15)^{\circ}$ and trans angles in the range 156.0(2)-158.17(14) ${ }^{\circ}$. When viewed perpendicular to the $b c$ plane, the disposition of the $\left[\mathrm{Mn}_{3}\right]$ cations resembles a honeycomb-type lattice where the MeCN molecules of crystallisation are H-bonded to the terminal bonded arm of the tripodal ligand $(\mathrm{N} \cdots \mathrm{O}$, approximately $2.8 \AA$ ), while the perchlorate anions are $\mathrm{H}$-bonded to the ring of carbon atoms $(\mathrm{O} \cdots \mathrm{H}-\mathrm{C}, \geq 2.3 \AA)$ and lie between the bpy groups of adjacent $\left[\mathrm{Mn}_{3}\right]$ molecules. The closest intermolecular contacts between cations occur between off-set $\pi$-stacked bpy groups (C… , approximately $3.5 \AA$ ).

a)

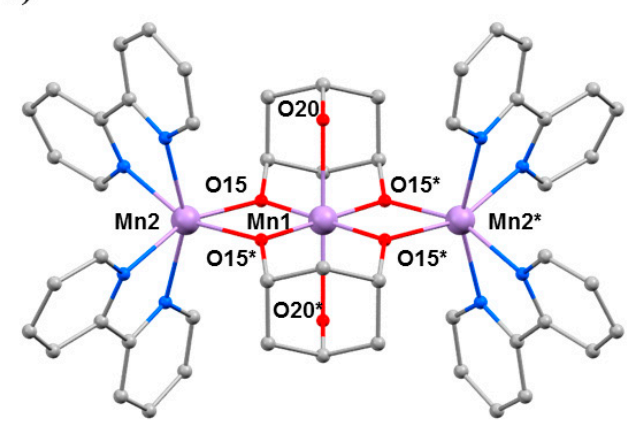

b)

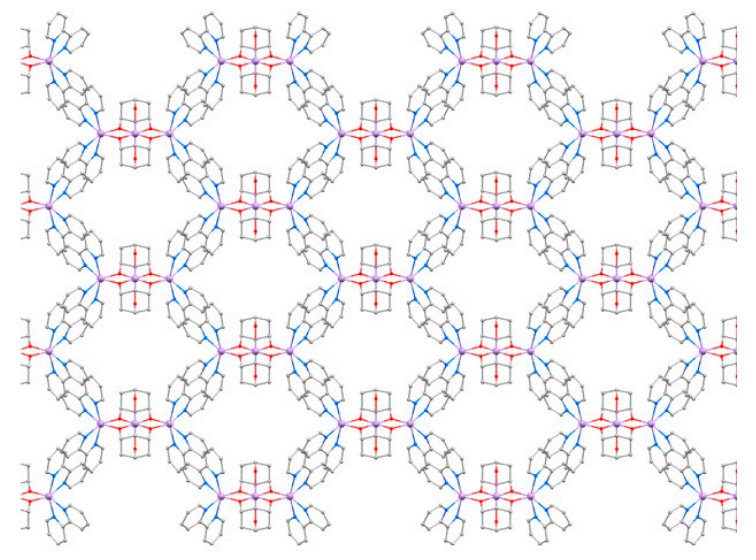

Figure 5. (a) The molecular structure of complex 3. (b) Packing of the cations of complex 3 viewed down the $a$-axis. Colour code: $\mathrm{Mn}=$ lilac, $\mathrm{O}=$ red, $\mathrm{N}=$ blue, $\mathrm{C}=$ grey. $\mathrm{H}$ atoms, solvent molecules and counterions are omitted for clarity.

HP single crystal XRD measurements were performed in petroleum ether at $T=300 \mathrm{~K}$ and three different pressures to a maximum of $1.25 \mathrm{GPa}$ [44]. Complex 3 crystallises in the monoclinic space group $I 2 / m$ and remains so in the full pressure range. Remarkably, by $0.16 \mathrm{GPa}$, there is complete elimination of the $\mathrm{MeCN}$ and $\mathrm{Et}_{2} \mathrm{O}$ solvent of crystallisation. It has literally been squeezed out of 
the crystal, representing the very first example of pressure-induced solvent elimination to have been observed from the crystal structure of any molecular coordination compound. This leaves large void spaces in the structure, equating to approximately $9.3 \%$ of the total volume that are gradually reduced to approximately $5.5 \%$ at $1.25 \mathrm{GPa}$. The total change in volume over the entire pressure range is approximately $10.5 \%$, resulting in intermolecular distances shortening by approximately $0.5 \AA$. For example, separations between $\mathrm{Mn}^{\mathrm{III}}$ ions along the three dimensions shift from 11.919(2), 13.385(2), and 22.044(4) $\AA$ at ambient pressure to 11.331(3), 13.586(3), and 21.547(4) $\AA$ at $1.25 \mathrm{GPa}$, respectively. Despite significant changes in intermolecular interactions, there are only minor intramolecular changes. The Mn-O15 bonds contract from 1.898(3) $\AA$ at ambient pressure to 1.858(5) $\AA$ at the highest pressure

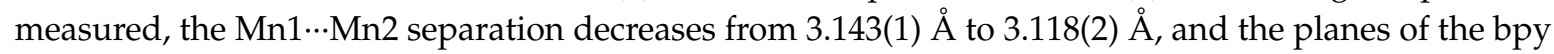
rings become a little more 'twisted' with respect to each other $\left(15.4(1)^{\circ} \rightarrow 16.6(2)^{\circ}\right)$.

Direct current (dc) magnetic susceptibility data collected at ambient pressure $(T=300-5 \mathrm{~K}$, $B=0.1 \mathrm{~T}$ ) reveal weak ferromagnetic exchange between the $\mathrm{Mn}^{\mathrm{III}}$ and $\mathrm{Mn}^{\mathrm{II}}$ ions with $J=+1.15 \mathrm{~cm}^{-1}$. Fitting of the magnetisation data $(T=2-7 \mathrm{~K}, B=1-7 \mathrm{~T})$ afforded the parameters $S=7, D=-0.17 \mathrm{~cm}^{-1}$ with $g=1.99$. With increasing pressure, the susceptibility data clearly indicate a weakening interaction, $\chi_{\mathrm{M}} T$ increases more slowly with the increasing pressure as the temperature decreases, reaching a smaller maximum at $T=5 \mathrm{~K}$. Simulation of the HP susceptibility data (Table 3 ) shows that the exchange decreases by close to $50 \%$, to a value of $J=+0.60 \mathrm{~cm}^{-1}$ at $0.85 \mathrm{GPa}$. This behaviour is consistent with the observed shortening of the Mn1-O15 bond distance and Mn1 ‥Mn2 separation, which would increase the antiferromagnetic contribution to the exchange. Magnetisation data at all pressures are super-imposable and can be fitted with the same parameter set as those obtained at ambient pressure, which is consistent with the lack of change in geometry at the JT distorted $\mathrm{Mn}^{\mathrm{III}}$ site and the retention of ferromagnetic nearest neighbour exchange.

Table 3. Comparison of the $J$ values and the energy differences between the ground state and first/second excited spin states at ambient pressure and at $0.85 \mathrm{GPa}$ for complex 3 as calculated from an isotropic fit of the susceptibility data.

\begin{tabular}{ccccc}
\hline$P / G P a$ & $S$ & $J / \mathbf{c m}^{-1}$ & $E_{1} / \mathbf{c m}^{-1}$ & $E_{2} / \mathbf{c m}^{-1}$ \\
\hline Ambient pressure & 7 & +1.15 & $4.6(S=6)$ & $9.2(S=5)$ \\
0.85 & 7 & +0.60 & $2.4(S=6)$ & $4.8(S=5)$ \\
\hline
\end{tabular}

The complex $\left[\mathrm{Mn}_{12} \mathrm{O}_{12}\left(\mathrm{O}_{2} \mathrm{CCH}_{2}{ }^{t} \mathrm{Bu}\right)_{16}\left(\mathrm{H}_{2} \mathrm{O}\right)_{4}\right] \cdot \mathrm{CH}_{2} \mathrm{Cl}_{2} \cdot \mathrm{MeNO}_{2}\left(4 \cdot \mathrm{CH}_{2} \mathrm{Cl}_{2} \cdot \mathrm{MeNO}_{2}\right)$ belongs to the prototype $\left[\mathrm{Mn}_{12} \mathrm{O}_{12}\left(\mathrm{O}_{2} \mathrm{CR}\right)_{16}\left(\mathrm{H}_{2} \mathrm{O}\right)_{4}\right]$ family of SMMs $[45,46]$. The general structure of these complexes consists of a ring of eight $\mathrm{Mn}^{\mathrm{III}}$ centres surrounding a central $\mathrm{Mn}^{\mathrm{IV}}{ }_{4} \mathrm{O}_{4}$ cube, which is bridged by oxide and carboxylate ligands (Figure 6). In the case of $\mathrm{Mn}_{12}$ acetate, the $\mathrm{Mn}^{\mathrm{III}}$ ions occupy two crystallographically independent sites with the eight JT axes lying in near alignment with the magnetic easy axis, affording $D=-0.457(2) \mathrm{cm}^{-1}$. In combination with a $S=10$ spin ground state, this leads to an effective barrier to magnetisation reversal of approximately $60 \mathrm{~K}$ [47]. However, bulk $\left[\mathrm{Mn}_{12}\right]$ samples often contain a small percentage of a fast-relaxing (FR) JT isomer, which display a misaligned/horizontal JT axis and a much lower barrier height, $U_{\text {eff }} \approx 40 \mathrm{~K}$, and initial HP studies of the static magnetic properties of $\mathrm{Mn}_{12}$ acetate at low temperatures, and HP inelastic neutron scattering (INS) measurements, had suggested some conversion of the slow relaxing (SR) isomer to the FR isomer with pressure [48-50]. However, both studies lacked any crystallographic confirmation. In order to address this, we turned our attention to $\left[\mathrm{Mn}_{12} \mathrm{O}_{12}\left(\mathrm{O}_{2} \mathrm{CCH}_{2}{ }^{t} \mathrm{Bu}\right)_{16}\left(\mathrm{H}_{2} \mathrm{O}\right)_{4}\right] \cdot \mathrm{CH}_{2} \mathrm{Cl}_{2} \cdot \mathrm{MeNO}_{2}\left(4 \cdot \mathrm{CH}_{2} \mathrm{Cl}_{2} \cdot \mathrm{MeNO}_{2}\right)$ because it exists as the $100 \%$ FR isomer, with the JT axis on Mn8 oriented equatorially rather than axially (Figure 6). 
a)

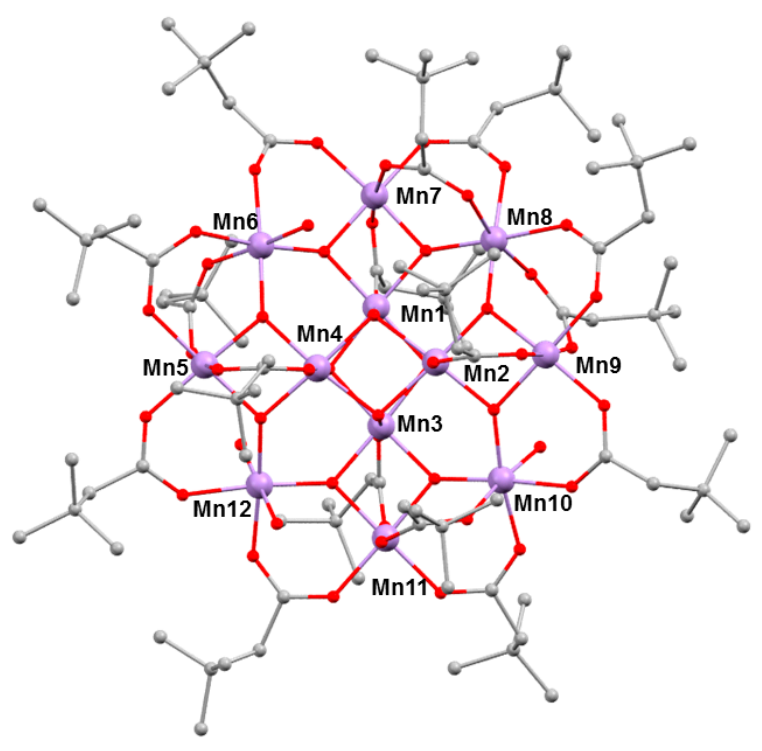

b)

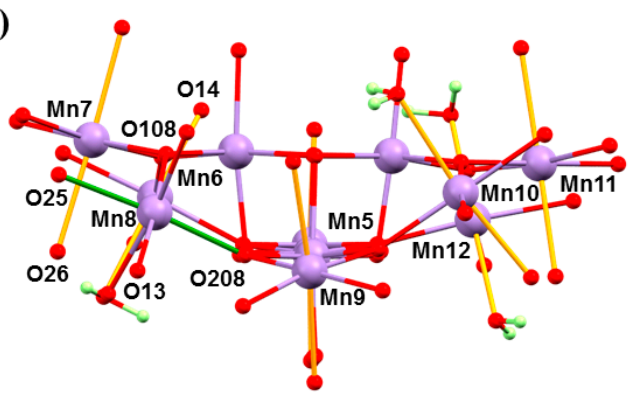

c)

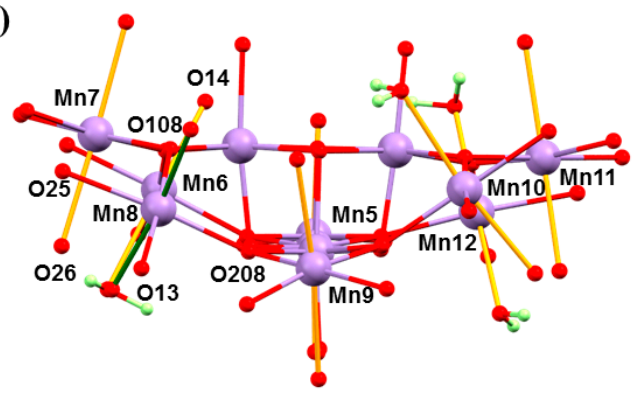

Figure 6. (a) The molecular structure of complex 4. (b) The structure of the Mn-O core of 4 at ambient pressure and (c) at $2.5 \mathrm{GPa}$. The 'vertical' JT bonds are coloured orange, and the JT bonds on Mn8, which switches with applied pressure, are coloured green. Colour code: $\mathrm{Mn}=$ lilac, $\mathrm{O}=$ red, $\mathrm{C}=$ grey, $\mathrm{H}=$ pale green. $\mathrm{H}$ atoms (except on $\mathrm{H}_{2} \mathrm{O}$ ligands shown in $(\mathbf{b}, \mathbf{c})$ ) and solvent molecules are omitted for clarity.

HP single crystal XRD measurements were performed in Daphne oil at $T=298 \mathrm{~K}$ and at three different pressures up to $2.5 \mathrm{GPa}$ [51]. Complex 4 crystallises in the triclinic space group $P-1$ and remains so in the full pressure range. At ambient pressure, the formula unit contains one $\mathrm{MeNO}_{2}$ and $\mathrm{CH}_{2} \mathrm{Cl}_{2}$ of solvation. At $1.5 \mathrm{GPa}$, the occupancies of the solvent decreases to $0.75 \mathrm{MeNO}_{2}$ and $0.5 \mathrm{CH}_{2} \mathrm{Cl}_{2}$ per formula unit, and at $2.5 \mathrm{GPa}$, the solvent is removed completely-suggesting that the solvent is released into the hydrostatic medium and reabsorbed on decompression. The main structural changes within the cluster occur at the $\mathrm{Mn}^{\mathrm{III}}$ centres. At $1.5 \mathrm{GPa}$, the JT elongated bonds on Mn5, Mn6, and Mn12 become more asymmetric, while those on Mn7 and Mn9-Mn11 decrease, but only by approximately $0.02 \AA$ on average. At Mn8, the JT bond (O208-Mn8-O25; 2.049(2) $\AA, 2.145(3) \AA)$ lengths decrease, and at $1.5 \mathrm{GPa}$, the six Mn-O distances span the range 1.94(2) to 2.082(15) $\AA$ (Table 4), suggesting that the disorder present at ambient pressure persists. At $2.5 \mathrm{GPa}$ (Figure 6), the horizontal JT bonds at Mn8 switch to vertical JT bonds, O14-Mn8-O26 (2.105(17) $\AA$, 2.19(2) $\AA$ ). Between 1.5 and $2.5 \mathrm{GPa}$, the JT bonds on the remaining $\mathrm{Mn}^{\mathrm{III}}$ sites do not change significantly. Release of pressure re-establishes the coordination seen at ambient pressure. Note that $\mathrm{FR} \rightarrow \mathrm{SR}$ isomer conversion had been previously reported to be affected by solvent loss, which is consistent with this HP crystallographic data [45,46].

Table 4. Mn-O bond lengths at Mn8 as a function of pressure. Values for significantly elongated bonds are shown in bold.

\begin{tabular}{cccccc}
\hline$T / K$ & 150 & 298 & 298 & 298 & 298 \\
\hline$P / G P a$ & 0 & 0 & 1.5 & 2.5 & 0 \\
\hline \multicolumn{7}{c}{ Distance/A } \\
\hline Mn8-O108 & $1.893(3)$ & $1.930(4)$ & $1.98(2)$ & $1.88(3)$ & $1.932(4)$ \\
Mn8-O13 & $1.963(3)$ & $2.002(5)$ & $2.02(3)$ & $1.89(3)$ & $1.994(4)$ \\
Mn8-O208 & $\mathbf{2 . 0 4 9 ( 2 )}$ & $1.966(4)$ & $1.94(2)$ & $1.90(3)$ & $1.956(4)$ \\
Mn8-O25 & $\mathbf{2 . 1 4 5 ( 3 )}$ & $2.025(4)$ & $2.04(3)$ & $2.03(3)$ & $2.022(5)$ \\
Mn8-O14 & $1.961(2)$ & $2.012(5)$ & $\mathbf{2 . 0 8 2 ( 1 5 )}$ & $\mathbf{2 . 1 0 5 ( 1 7 )}$ & $2.015(5)$ \\
Mn8-O26 & $1.956(3)$ & $2.010(5)$ & $2.034(17)$ & $\mathbf{2 . 1 9 ( 2 )}$ & $2.005(5)$ \\
\hline
\end{tabular}


High-pressure alternating current (ac) susceptibility data (Figure 7) from ambient pressure to a maximum of $1.44 \mathrm{GPa}$ was collected in Daphne oil. The ambient pressure data reveals only one peak at low temperature $\left(T_{\max }=2.1 \mathrm{~K}\right.$ at $\left.1 \mathrm{~Hz}\right)$ due to the FR species. At $0.47 \mathrm{GPa}$, the low temperature peak shifts to higher temperature (approximately $2.3 \mathrm{~K}$ ) with a significant decrease in its intensity, and a new broader peak appears at approximately $4 \mathrm{~K}$, i.e., both FR and SR isomers are now present. This trend continues to higher pressures, and at $1.44 \mathrm{GPa}$, the low temperature peak disappears and only the high temperature peak is observed $\left(T_{\max }=4.1 \mathrm{~K}\right.$ at $\left.1 \mathrm{~Hz}\right)$ due to the exclusive presence of the SR species. The switch is fully reversible. Arrhenius analysis of the frequency dependence affords $U_{\text {eff }}(F R)=41 \mathrm{~K}$, $\tau_{0}=4 \times 10^{-10} \mathrm{~s}$, increasing to $U_{\mathrm{eff}}(\mathrm{FR})=46 \mathrm{~K}, \tau_{0}=8 \times 10^{-10} \mathrm{~s}$ at $1.12 \mathrm{GPa}$. The energy barrier of the pressure-induced SR species, $U_{\text {eff }}(S R)=63 \mathrm{~K}$, compares well to the value, $U_{\text {eff }}=62 \mathrm{~K}$, which was previously reported for the SR species $\left[\mathrm{Mn}_{12} \mathrm{O}_{12}\left(\mathrm{O}_{2} \mathrm{CCH}_{2}{ }^{t} \mathrm{Bu}\right)_{16}\left(\mathrm{H}_{2} \mathrm{O}\right)_{4}\right] \cdot \mathrm{CH}_{2} \mathrm{Cl}_{2} \cdot \mathrm{MeCN}$. The switch from $\mathrm{FR} \rightarrow \mathrm{SR}$ isomer is also evidenced in the evolution of the hysteresis loop under pressure at $2 \mathrm{~K}$ (Figure 7), whose coercive field increases with pressure. An estimation of the axial zero-field splitting $(z f s)$ from the $1.44 \mathrm{GPa}$ magnetisation data affords, $D=-0.61 \mathrm{~K}$, which is in excellent agreement with that obtained from single-crystal low-temperature hysteresis loops.
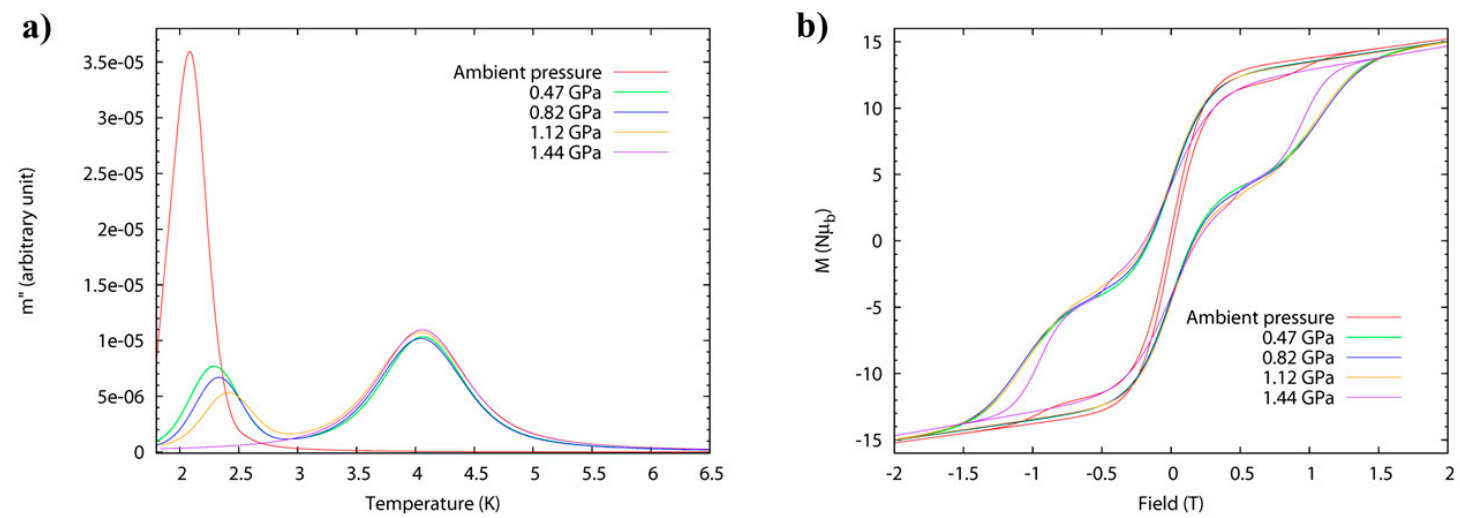

Figure 7. (a) High-pressure ac susceptibility data for compound 4 measured at a fixed frequency of $1 \mathrm{~Hz}$ (left). Conversion of the fast-relaxing (FR) to the slow-relaxing (SR) species can be seen through the disappearance of the peak at approximately $2 \mathrm{~K}$ and the emergence of the peak at approximately $4 \mathrm{~K}$. (b) High-pressure hysteresis loops for 4 at $T=2 \mathrm{~K}$ from ambient to $1.44 \mathrm{GPa}$.

The compounds $\left[\mathrm{Mn}_{2} \mathrm{O}_{2}(\mathrm{bpy})_{4}\right]\left(\mathrm{ClO}_{4}\right)_{3} \cdot 3 \mathrm{MeCN}(5 \cdot 3 \mathrm{MeCN})$ and $\left[\mathrm{Mn}_{2} \mathrm{O}_{2}(\mathrm{bpy})_{4}\right]\left(\mathrm{PF}_{6}\right)_{3} \cdot 2 \mathrm{MeCN} \cdot \mathrm{H}_{2} \mathrm{O}$ $\left(6 \cdot 2 \mathrm{MeCN} \cdot \mathrm{H}_{2} \mathrm{O}\right)$ belong to a family of mixed-valence oxo-bridged $\mathrm{Mn}{ }^{\mathrm{III}} / \mathrm{Mn}^{\mathrm{IV}}$ dimers originally synthesised as models for metalloenzymes [52]. Their structures (Figure 8) contain a central $\left[\mathrm{Mn}^{\mathrm{III}} \mathrm{Mn}^{\mathrm{IV}} \mathrm{O}_{2}\right]^{3+}$ asymmetric core with two bridging $\mu-\mathrm{O}^{2-}$ ligands and two 2,2'-bipyridine (bpy) ligands completing the octahedral coordination around each $\mathrm{Mn}$ ion. Charge balance is maintained by the presence of three $\left[\mathrm{ClO}_{4}\right]^{-}(5 \cdot 3 \mathrm{MeCN})$ or three $\left[\mathrm{PF}_{6}\right]^{-}\left(6 \cdot 2 \mathrm{MeCN} \cdot \mathrm{H}_{2} \mathrm{O}\right)$ counter ions. $\mathrm{Mn} 1$ is in the $3+$ oxidation state, with the JT axis defined by the N29-Mn1-N41 vector, which lies approximately perpendicular to the $\left[\mathrm{Mn}_{2} \mathrm{O}_{2}\right]$ plane. The $\mathrm{Mn}-\mathrm{Mn}$ separation and the $\mathrm{Mn}-\mathrm{O}-\mathrm{Mn}$ bridging angles are 2.7058(4) $\AA, 96.42(7)^{\circ}, 96.09(7)^{\circ}$ in $5 \cdot 3 \mathrm{MeCN}$ and $2.7177(7) \AA, 97.00(11)^{\circ}, 96.97(11)^{\circ}$ in $6 \cdot 2 \mathrm{MeCN} \cdot \mathrm{H}_{2} \mathrm{O}$. In both cases, the solvent molecules and anions are hydrogen bonded to the protons of the bpy ligands, and the closest inter-cluster interaction is between staggered $\pi-\pi$ stacked bpy rings. 
a)

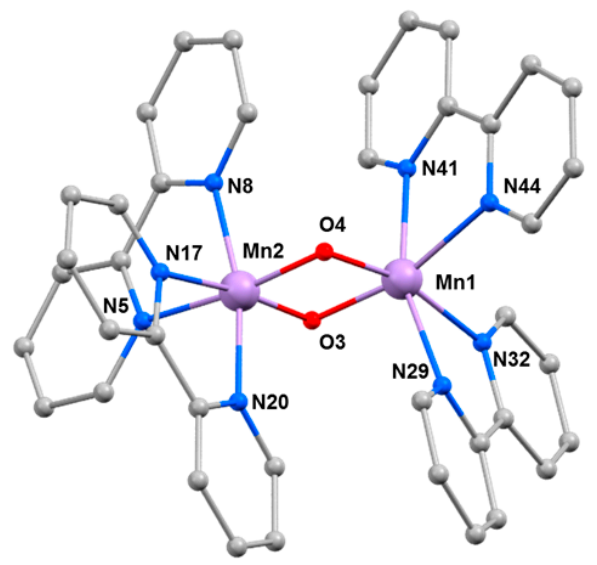

b)

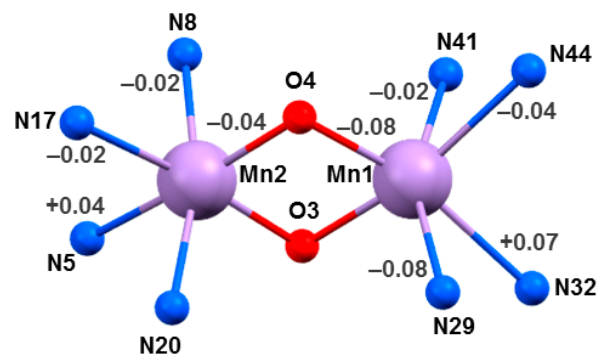

Figure 8. (a) The molecular structure common to complexes 5.3MeCN and 6.2MeCN. $\mathrm{H}_{2} \mathrm{O}$. (b) Variations in the bond lengths from ambient pressure to $2.00 \mathrm{GPa}$ in $5 \cdot 3 \mathrm{MeCN}$. Only statistically significant changes are shown. Colour code: $\mathrm{Mn}=$ lilac, $\mathrm{O}=$ red, $\mathrm{N}=$ blue, $\mathrm{C}=$ grey. $\mathrm{H}$ atoms, counterions and solvent molecules are omitted for clarity.

HP single-crystal XRD measurements were performed in petroleum ether at room temperature [53]. Data were collected at four different pressures to a maximum pressure of $2.00 \mathrm{GPa}$ for $\mathbf{5}$ and six different pressures to a maximum pressure of $4.55 \mathrm{GPa}$ for $\mathbf{6}$. Complex 5 crystallises in the triclinic space group $P-1$, and complex 6 crystallises in the monoclinic space group $P 2_{1} / n$; both remain in the same space groups in the full pressure range. The main effect of applying pressure is the contraction of the unit cell volume $\left(2517.49(9) \rightarrow 2239.1(11) \AA^{3} ; 5150.7(2) \rightarrow 4207.5(6) \AA^{3}\right.$, respectively), due to the reduction of void space and aided by the lack of any significant intermolecular interactions. The main intramolecular changes are to the Mn-Mn distance, which contracts from 2.7058(4) $\rightarrow$ 2.676(4) $\AA$ at 2.0 GPa in 5 and from 2.7177(7) $\rightarrow 2.672(3) \AA$ at $4.55 \mathrm{GPa}$ in $\mathbf{6}$. In the case of 5 , this change is likely due to the contraction of both $\mathrm{Mn}-\mathrm{O} 4$ bonds (Table 5); however, for 6, the variations observed for the $\mathrm{Mn}-\mathrm{O}$ distances and the $\mathrm{Mn}-\mathrm{O}-\mathrm{Mn}$ angles are not statistically significant. In 5, there are also significant changes in the Mn1-N bond lengths, which see two of the four decreasing and one (N32) increasing. The JT axis (N41-Mn1-N29) is significantly shortened, with the Mn1-N29 bond contracting from 2.2221(18) $\AA$ to 2.142(6) $\AA$. For Mn2, the changes are less significant, except for the Mn2-N5 bond, which increases from 2.078(5) $\AA$ at 0.18 GPa to 2.144(8) $\AA$ at 2.00 GPa. A similar change is also seen in 6 .

Table 5. Selected bond lengths $(\AA)$ and angles $\left({ }^{\circ}\right)$ for $5 \cdot 3 \mathrm{MeCN}$ and $6 \cdot 2 \mathrm{MeCN} \cdot \mathrm{H}_{2} \mathrm{O}$ at ambient and maximum pressure.

\begin{tabular}{ccccc}
\hline & \multicolumn{2}{c}{$5 \cdot 3 \mathrm{MeCN}$} & \multicolumn{2}{c}{$\mathbf{6} \mathbf{2} \mathbf{M e N} \cdot \mathbf{H}_{\mathbf{2}} \mathbf{O}$} \\
\cline { 2 - 5 } & Ambient Pressure & $\mathbf{2 . 0 0} \mathbf{G P a}$ & Ambient Pressure & $\mathbf{4 . 5 5} \mathbf{G P a}$ \\
\hline Mn1-O3 & $1.8419(15)$ & $1.817(11)$ & $1.847(2)$ & $1.828(10)$ \\
Mn1-O4 & $1.8621(15)$ & $1.78(2)$ & $1.850(2)$ & $1.821(11)$ \\
Mn1-N44 & $2.1093(19)$ & $2.072(8)$ & $2.134(3)$ & $2.084(9)$ \\
Mn1-N41 & $2.2053(18)$ & $2.194(7)$ & $2.220(3)$ & $2.156(8)$ \\
Mn1-N32 & $2.1666(19)$ & $2.245(16)$ & $2.2128(3)$ & $2.085(9)$ \\
Mn1-N29 & $2.2221(18)$ & $2.142(6)$ & $2.212(3)$ & $2.148(8)$ \\
Mn2-O3 & $1.7867(15)$ & $1.79(2)$ & $1.781(2)$ & $1.752(12)$ \\
Mn2-O4 & $1.7753(15)$ & $1.740(10)$ & $1.779(2)$ & $1.791(11)$ \\
Mn2-N5 & $2.0971(18)$ & $2.144(8)$ & $2.077(3)$ & $2.029(8)$ \\
Mn2-N8 & $2.0160(18)$ & $2.002(6)$ & $2.008(3)$ & $1.998(8)$ \\
Mn2-N17 & $2.0813(18)$ & $2.060(13)$ & $2.078(3)$ & $2.017(9)$ \\
Mn2-N20 & $2.0165(18)$ & $2.021(5)$ & $2.017(3)$ & $1.982(8)$ \\
Mn1-Mn2 & $2.7058(4)$ & $2.676(4)$ & $2.7177(7)$ & $2.672(3)$ \\
\hline Mn1-O3-Mn2 & $96.42(7)$ & $95.6(11)$ & $97.00(11)$ & $96.5(4)$ \\
Mn1-O4-Mn2 & $96.09(7)$ & $98.7(11)$ & $96.97(11)$ & $95.4(5)$ \\
\hline
\end{tabular}


High pressure dc susceptibility data $(T=350-20 \mathrm{~K}, B=0.1 \mathrm{~T})$ were collected to a maximum pressure of $0.87(0.84)$ GPa for 5(6) using Daphne oil as hydrostatic medium. The behaviour of both complexes is analogous to that previously reported for 5(6) across the whole temperature and pressure regime, which is consistent with the lack of any significant intramolecular structural change at low pressures. Simulations of the susceptibility data afford $J=-177 \mathrm{~cm}^{-1}$ and $g=1.96$ for 5 and $J=-185 \mathrm{~cm}^{-1}$ and $g=1.98$ for 6 .

\section{Cu Complexes}

The choice of investigating $\mathrm{Cu}^{\mathrm{II}}$ complexes was partly influenced by our initial success in $\mathrm{Mn}^{\mathrm{III}}$ chemistry where we repeatedly saw large structural changes associated with JT axes. Aligned with this was the well-known coordinative flexibility of the $\mathrm{Cu}^{\mathrm{II}}$ ion, which is commonly four, five, or six coordinate, adopting a variety of geometries, and consequently, colours. Therefore, such species offered another potential variable to examine high-pressure absorption/emission spectroscopy, which would allow us to correlate changes in the metal coordination sphere to piezochromism. The $\mathrm{Cu}$ dimer $[\mathrm{GuH}]\left[\mathrm{Cu}_{2}(\mathrm{OH})(\mathrm{cit})(\mathrm{Gu})_{2}\right]\left(7, \mathrm{H}_{4}\right.$ cit = citric acid, $\mathrm{Gu}=$ guanidine $)$ is somewhat unusual, in that it was the first reported example of a coordination compound containing neutral guanidine ligands bonded to a transition metal ion (Figure 9) [54]. At ambient pressure, complex 7 crystallises in the orthorhombic space group Pnma. The two $\mathrm{Cu}^{\mathrm{II}}$ ions have a distorted square pyramidal $[4+1]$ coordination environment. They are bridged by a $\mu-\mathrm{OH}^{-}$ligand (O6), the citrate alkoxide (O1), and the citrate $\alpha$-carboxylate group (O4). The latter forms the long 'axial' bond $(\mathrm{Cu} 1 \cdots \mathrm{O} 4,2.740(4) \AA)$. The coordination environment of each metal ion is completed by one citrate $\beta$-carboxylate $(\mathrm{O} 2)$ and one neutral guanidine ligand (N1). The region of the sixth coordination site of the $\mathrm{Cu}^{\mathrm{II}}$ ion is occupied by an uncoordinated $\beta$-carboxylate $\mathrm{O}$-atom from a neighbouring molecule $\left(\mathrm{Cu} 1 \cdots \mathrm{O} 3,3.217(4) \AA\right.$. The $\mathrm{GuH}^{+}$ cation is located in a pocket between the two neutral $\mathrm{Gu}$ ligands and is H-bonded to the anion.

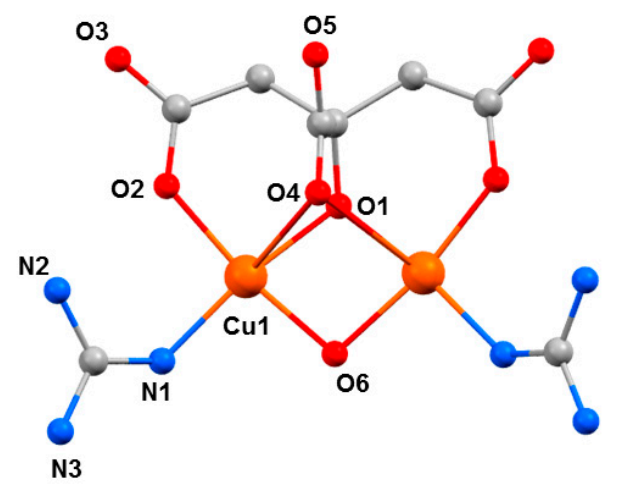

Figure 9. The molecular structure of the anion in 7. Colour code: $\mathrm{Cu}=$ orange, $\mathrm{O}=$ red, $\mathrm{N}=$ blue, $\mathrm{C}=$ grey. $\mathrm{H}$ atoms and the counter cation are omitted for clarity.

HP single-crystal XRD measurements were performed in pentane-isopentane at room temperature at four different pressures, to a maximum of $4.23 \mathrm{GPa}$. Little intramolecular changes are seen to $1.8 \mathrm{GPa}$,

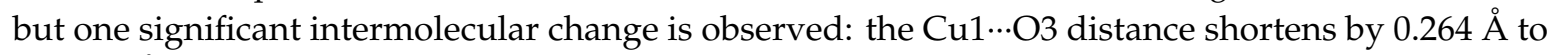
2.953(2) A. On increasing the pressure to $2.9 \mathrm{GPa}$, complex 7 undergoes a single-crystal-to-single-crystal phase transition to the non-centrosymmetric space group $P 2{ }_{1} 2{ }_{1}{ }_{1}$ (Phase II). The Cu1 $\cdots \mathrm{O} 3$ contact

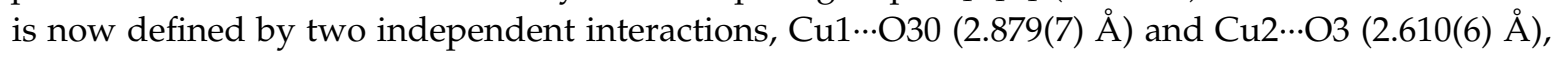
and the metal coordination environment changes from $[4+1] \rightarrow[4+2]$ with the long contacts now defined by the intramolecular $\mathrm{Cu}-\mathrm{O} 4$ bond and the intermolecular $\mathrm{Cu} 1-\mathrm{O} 30(\mathrm{Cu} 2-\mathrm{O} 3)$ contact. The result of these changes is the formation of a polymer via the conversion of intermolecular contacts to intramolecular bonds (Figure 10): the first example of the polymerisation of a transition metal complex with pressure. A second single-crystal-to-single-crystal phase transition occurs between 2.95 GPa and $4.23 \mathrm{GPa}$, this time to the centrosymmetric monoclinic space group $P 2_{1} / c$, forming Phase 
III, which consists of two crystallographically independent polymeric chains. One of these chains (based on Cu1, Cu2) remains largely unchanged, while the other (based on Cu10, Cu20) undergoes significant rearrangement. Specifically, the bridging $\alpha$-carboxylate ligand twists, forcing the $\mathrm{Cu}-\mathrm{O}-\mathrm{Cu}$ moiety to be more asymmetric, the $\mathrm{Cu} 10-\mathrm{O} 44$ and $\mathrm{Cu} 20-\mathrm{O} 44$ bonds measuring 2.816(7) and 2.497(7) $\AA$, respectively. Simultaneously, one polymer-forming bond, Cu10-O330, shortens to 2.449(6) $\AA$,

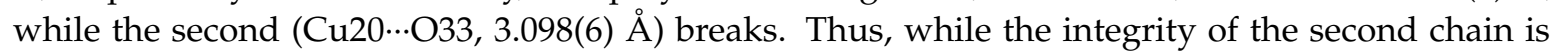
retained, the polymerisation only involves only one $\mathrm{Cu}^{\mathrm{II}}$ centre, i.e., half the $\mathrm{Cu}^{\mathrm{II}}$ ions become $[4+1]$ coordinate again.

a) Phase I

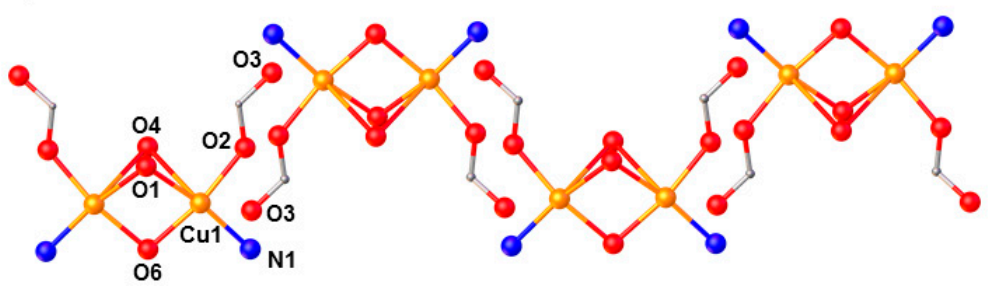

b) Phase II

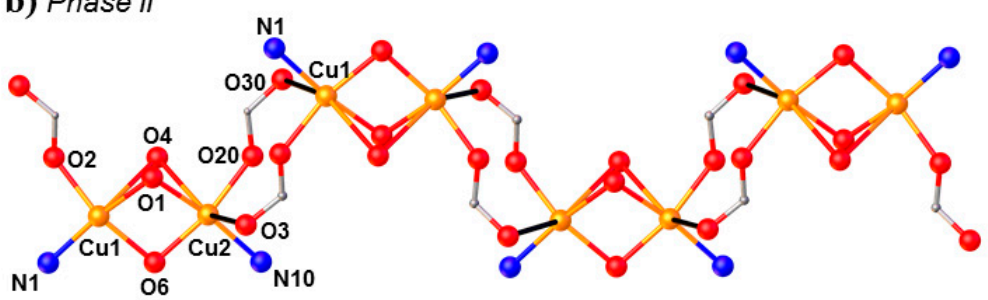

c) Phase IIla

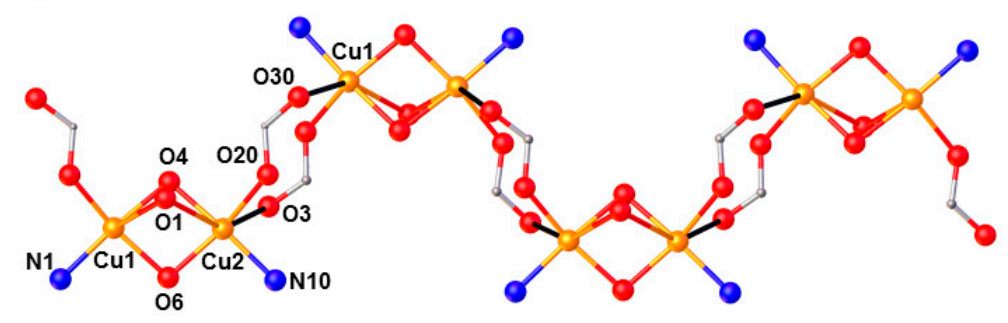

d) Phase IIIb

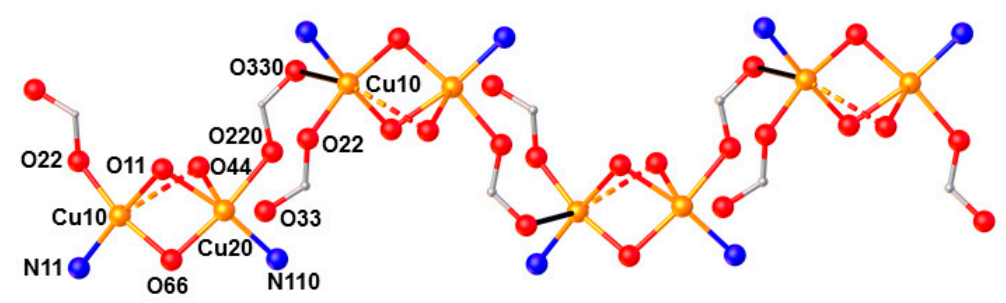

Figure 10. (a) The arrangement of the molecules in Phase I at ambient pressure. (b) Formation of the polymer in Phase II at $2.95 \mathrm{GPa}$. (c,d) The two crystallographically independent polymer chains of Phase III at $4.23 \mathrm{GPa}$. Colour code: $\mathrm{Cu}=$ orange, $\mathrm{O}=$ red and $\mathrm{N}=$ blue. $\mathrm{H}$ atoms and most uncoordinated atoms are omitted for clarity. 
A second, structurally related citrate/guanidine-based $\mathrm{Cu}^{\mathrm{II}}$ dimer, $[\mathrm{GuH}]_{4}\left[\mathrm{Cu}_{2}\left(\mathrm{cit}_{2}\right] \cdot 2 \mathrm{H}_{2} \mathrm{O}(8)\right.$, was also studied [55]. Compound 8 (Figure 11) crystallises in the orthorhombic space group Pbca and consists of two symmetry equivalent $\mathrm{Cu}^{\mathrm{II}}$ ions bridged by two alkoxide $\mathrm{O}$-atoms (O7 and s.e.) from the citrate ligands, the metals being further coordinated by the $\beta$-carboxylate $\mathrm{O}$-atoms from each ligand $(\mathrm{O} 1, \mathrm{O} 3)$. The four-coordinate, pseudo-tetrahedral metal centre has approximate $D_{2 d}$ symmetry. In addition, each $\alpha$-carboxylate group is oriented toward one of the $\mathrm{Cu}^{\mathrm{II}}$ centres at a $\mathrm{Cu} 1-\mathrm{O} 5$ distance of 2.628(3) $\AA$, with the O5-Cu-Cu angle being $73.05(6)^{\circ}$. Therefore, an alternative description of the coordination sphere of the metal centre is a highly distorted [4 +1$]$ geometry.

a)

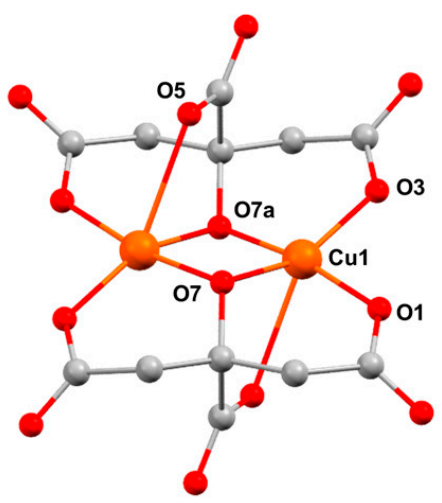

b)

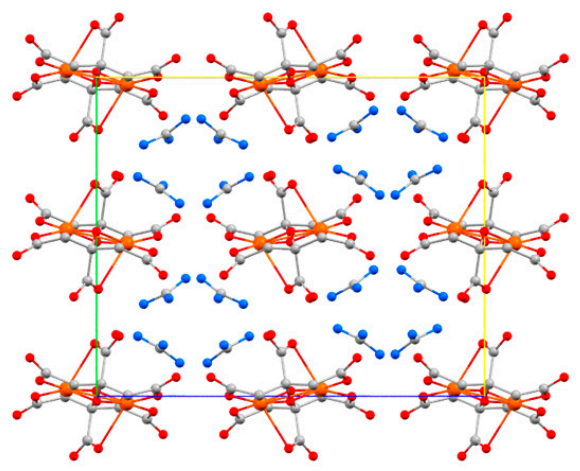

Figure 11. (a) The molecular structure of the anion in 8. (b) Crystal packing of complex 8 along the $a$-axis. Colour code: $\mathrm{Cu}=$ orange, $\mathrm{O}=$ red, $\mathrm{N}=$ blue, $\mathrm{C}=$ grey. $\mathrm{H}$ atoms and counter ions (in (a)) are omitted for clarity.

HP single-crystal XRD measurements were performed on 8 in a 1:1 mixture of pentane-isopentane to a maximum pressure of $2.20 \mathrm{GPa}$. The crystal packing of 8 consists of alternate layers of cations and anions (Figure 11b), in which the $\mathrm{GuH}^{+}$ions direct an extensive hydrogen-bonding network with the citrate ligand $\mathrm{O}$-atoms and lattice $\mathrm{H}_{2} \mathrm{O}$ molecules. The main effect of applying pressure is a compression along the direction of the layer-stacking in the $b$-axis (which also contains the largest voids), which decreases in length by $8.9 \%$ to $2.20 \mathrm{GPa}(14.713(9) \AA \rightarrow 13.4098(7) \AA)$. The shortening of the $a$ and $b$ axes allied to the diamond-like packing motifs formed by the guanadinium cations causes the $c$ axis to lengthen, which is an early example of negative linear compressibility in molecular solids. The most significant intramolecular change is in the $\mathrm{Cu}-\mathrm{O} 5$ distance, which decreases from 2.628(3) $\AA$ at ambient pressure to $2.407(3) \AA$ at $2.20 \mathrm{GPa}$. Therefore, the metal geometry is now 5-coordinate $[4+1]$ with approximate $C_{4 \mathrm{v}}$ symmetry. Interestingly, the $\mathrm{Cu}-\mathrm{O} 5$ bonds also lie along the $b$-axis, meaning that the largest intramolecular compression correlates with the largest intermolecular compression. $\mathrm{HP}$ single-crystal electronic spectroscopy measurements reveal that 8 undergoes a colour change from blue to green, which is due to a reduction in absorption in the $18,500-14,000 \mathrm{~cm}^{-1}$ region. This is directly related to the reduction in the $\mathrm{Cu}-\mathrm{O} 5$ bond length and the rearrangement of the $\mathrm{Cu}$ coordination sphere. The $\mathrm{d}-\mathrm{d}$ spectrum (Figure 12) at ambient pressure consists of two bands at 15,300 and $12,800 \mathrm{~cm}^{-1}$, which are observed in the full pressure range to a maximum of $5.5 \mathrm{GPa}$. Both bands blue shift linearly with pressure at a rate of 140 and $100 \mathrm{~cm}^{-1} \mathrm{GPa}^{-1}$, respectively. The $15,300 \mathrm{~cm}^{-1}$ band intensity decreases with pressure and almost disappears above $2.5 \mathrm{GPa}$. The intensity ratio in the $0-2.5 \mathrm{GPa}$ range decreases in line with the reduction in the $\mathrm{Cu}-\mathrm{O} 5$ distance, suggesting this to be chiefly responsible for the observed piezochromism. The main effects observed in the electronic spectra can be explained in terms of simple monomeric $\mathrm{Cu}^{\mathrm{II}}$ units (Figure 12b). At ambient pressure, the $\mathrm{Cu}-\mathrm{O} 5$ interaction is weak, and though the $\mathrm{Cu}$ site symmetry is $C_{1}$, the spectrum can be interpreted by considering a pseudo-tetrahedral $\left(D_{2 d}\right)$ 4-coordinate $\mathrm{Cu}$ moiety, showing two allowed transitions $\left(\mathrm{e} \rightarrow \mathrm{b}_{2}\right.$ and $\mathrm{a}_{1}$ $\rightarrow b_{2}$ ). At higher pressures, the $\mathrm{Cu}-\mathrm{O} 5$ interaction becomes much shorter, and the spectrum can be interpreted by considering a single allowed transition in the $\left(C_{4 v}\right) 5$-coordinate $C u$ moiety $\left(e \rightarrow b_{2}\right)$. In short, the gradual reduction of the 'axial' $\mathrm{Cu}-\mathrm{O}$ bond length induces a continuous transformation 
of the local $\mathrm{Cu}$ site symmetry from approximately $D_{2 \mathrm{~d}}$ at ambient pressure to approximately $C_{4 \mathrm{v}}$, in which $e \rightarrow b_{2}$ is the only allowed transition.

a)

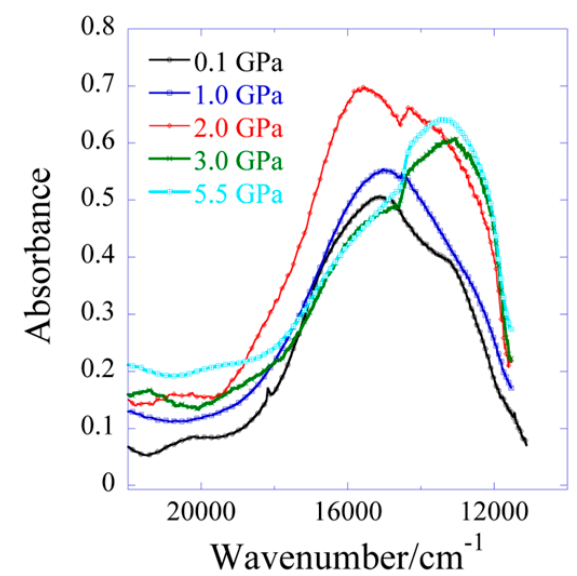

b)
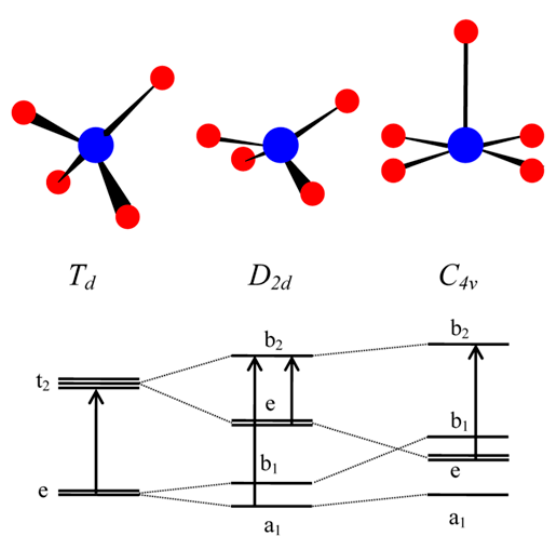

Figure 12. (a) Electronic absorption of complex 8 at different pressures (up to $5.5 \mathrm{GPa}$ ) at ambient temperature. (b) Correlation diagram showing the energy level structure of 4-coordinate $\mathrm{Cu}^{\mathrm{II}}$ from $T_{\mathrm{d}}$ to $D_{2 \mathrm{~d}}$, and 5-coordinate from $D_{2 \mathrm{~d}}$ to $C_{4 \mathrm{v}}$. The arrows indicate symmetry allowed transitions.

The complexes $\left[\mathrm{Cu}_{2}(\mathrm{OH})_{2}\left(\mathrm{H}_{2} \mathrm{O}\right)_{2}(\mathrm{tmen})_{2}\right]\left(\mathrm{ClO}_{4}\right)_{2}(\mathbf{9}$, tmen = tetramethylethylenediamine $)$, $\left[\mathrm{Cu}_{2}(\mathrm{OH})_{2}(\text { tben })_{2}\right]\left(\mathrm{ClO}_{4}\right)_{2}\left(\mathbf{1 0}\right.$, tben $=$ di- ${ }^{t}$ butylethylenediamine $)$, and $\left[\mathrm{Cu}_{2}(\mathrm{OH})_{2}(\mathrm{bpy})_{2}\right]\left(\mathrm{BF}_{4}\right)_{2}(\mathbf{1 1}$, bpy $=2,2^{\prime}$-bipyridine) are part of a large family of hydroxo-bridged $\mathrm{Cu}^{\mathrm{II}}$ dimers that have been studied since the 1970s when Hatfield and Hodgson first developed a quantitative magneto-structural correlation relating the bridging $\mathrm{Cu}-\mathrm{II}-\mathrm{O}-\mathrm{Cu}^{\mathrm{II}}$ angles in the diamond-shaped $\left[\mathrm{Cu}_{2}(\mu-\mathrm{OH})_{2}\right]$ core to the magnitude of the exchange interaction [56]. Complex 9 (Figure 13) has each $\mathrm{Cu}^{\mathrm{II}}$ ion in a $\left[\mathrm{CuO}_{3} \mathrm{~N}_{2}\right]$ square pyramidal coordination sphere, while in $\mathbf{1 0}$, the bulky ${ }^{t} \mathrm{Bu}$ groups of the then ligands force the geometries of the metal ions to be intermediate between square planar and tetrahedral, with additional solvent ligation impossible, such that the $\mathrm{Cu}^{\mathrm{II}}$ ions are four coordinate with $\left[\mathrm{CuO}_{2} \mathrm{~N}_{2}\right]$ coordination spheres (Figure 14a). The $\mathrm{Cu}^{\mathrm{II}}$ ions in $\mathbf{1 1}$ are in a JT distorted $\left[\mathrm{CuO}_{2} \mathrm{~N}_{2} \mathrm{~F}_{2}\right]$ octahedral geometry, with the $\mathrm{F}-\mathrm{Cu}-\mathrm{F}$ vector defining the JT axis (Figure $14 \mathrm{~b}$ ). The $\mathrm{Cu}-\mathrm{O}-\mathrm{Cu}$ angles are $102.03(13)^{\circ}$ in $9,102.72(6)^{\circ}$ and $101.62(6)^{\circ}$ in 10, and $97.40(14)^{\circ}$ in 11. At ambient pressure, they crystallise in the monoclinic space groups $P 2_{1} / c(\mathbf{9}), C 2 / c(\mathbf{1 0})$, and $C 2 / m(\mathbf{1 1})$.

a)

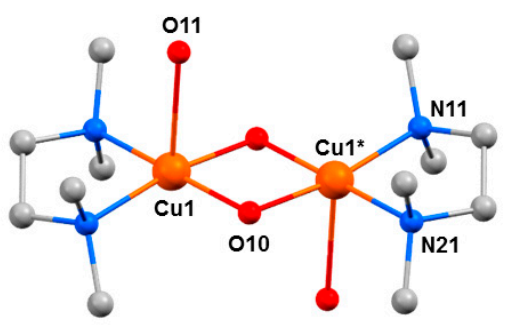

b)

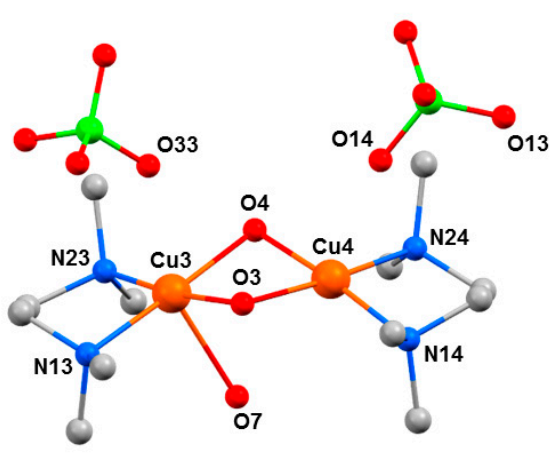

Figure 13. The molecular structure of complex 9 at (a) $0.25 \mathrm{GPa}$ and (b) $2.5 \mathrm{GPa}$. Colour code: $\mathrm{Cu}=$ orange, $\mathrm{O}=$ red, $\mathrm{N}=$ blue, $\mathrm{C}=$ grey, $\mathrm{Cl}=$ green. $\mathrm{H}$ atoms (and counterions in (a)) are omitted for clarity. 
a)

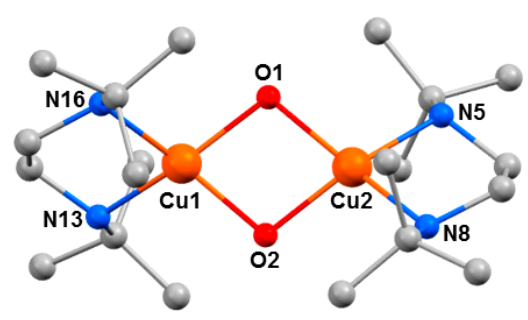

b)

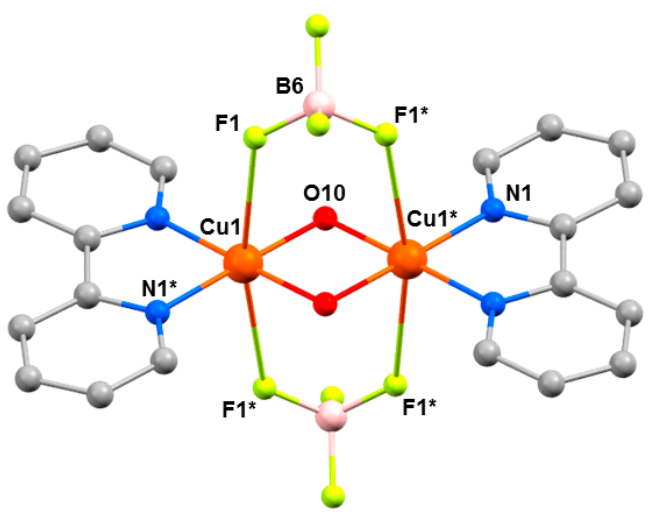

Figure 14. (a) The molecular structure of complex 10 at ambient pressure. (b) The molecular structure of complex 11 at ambient pressure. Colour code: $\mathrm{Cu}=$ orange, $\mathrm{O}=$ red, $\mathrm{N}=$ blue, $\mathrm{C}=$ grey, $\mathrm{B}=$ pink, $\mathrm{F}=$ pale green. $\mathrm{H}$ atoms (and counterions in (a)) are omitted for clarity.

HP single-crystal XRD measurements were performed using petroleum ether as hydrostatic medium [57]. Data were collected at 0.25, 0.70, 1.20, and 2.50 GPa for 9, at 0.21 and $0.90 \mathrm{GPa}$ for $\mathbf{1 0}$, and at $0.30,0.80,1.53,2.25,2.80,3.50,4.00,4.30$, and $4.70 \mathrm{GPa}$ for $\mathbf{1 1}$. Crystals of $\mathbf{1 0}$ and $\mathbf{1 1}$ remain in the same space group in the full pressure range, whereas complex 9 undergoes a phase transition between 1.20 and $2.50 \mathrm{GPa}$ from monoclinic $P 2_{1} / c$ to triclinic $P-1$. In all cases, the primary effect of applying pressure is a reduction of the unit cell, the compressions being assigned to the removal of void space due to the absence of any significant intermolecular interactions. The secondary effect is intramolecular. In 9, the $\mathrm{Cu}-\mathrm{O}-\mathrm{Cu}$ angle becomes smaller, from $102.03(13)^{\circ}$ to $99.7(7)^{\circ}$ at $1.20 \mathrm{GPa}$, with a concomitant shortening of the $\mathrm{Cu} \cdots \mathrm{Cu}$ distance from 2.9784(12) $\AA$ to 2.939(3) $\AA$ (Table 6). At ambient pressure, one $\mathrm{H}_{2} \mathrm{O}$ molecule is bonded to each $\mathrm{Cu}^{\mathrm{II}}$ ion, which is approximately perpendicular to the $\mathrm{Cu}_{2} \mathrm{O}_{2}$ plane $\left(\mathrm{Cu}-\mathrm{Cu}-\mathrm{O}=91.41(16)^{\circ}\right.$; Figure 13), but it becomes severely distorted at higher pressures $\left(\mathrm{Cu}-\mathrm{Cu}-\mathrm{O}=80.4(7)^{\circ}\right)$. The reason for this bending appears to be the shortening of the intermolecular $\mathrm{O}\left(\mathrm{ClO}_{4}\right) \cdots \mathrm{O}\left(\mathrm{H}_{2} \mathrm{O}\right)$ distance to just $3.50 \AA$. Further increases in pressure lead to a phase transition from the monoclinic space group $P 2_{1} / c$ to the triclinic space group $P-1$ between 1.20 and $2.50 \mathrm{GPa}$, with the asymmetric unit now containing two full dimers and four perchlorate anions. The loss of symmetry is caused by the elimination of one $\mathrm{H}_{2} \mathrm{O}$ molecule from half the dimers, producing two different complexes: one with two $\mathrm{H}_{2} \mathrm{O}$ molecules (one bonded to $\mathrm{Cu} 1$ and $\mathrm{Cu} 1^{*}$ ) and one with only one $\mathrm{H}_{2} \mathrm{O}$ molecule (bonded to $\mathrm{Cu} 3$; Figure 13). This was the first reported example of pressure-induced $\mathrm{H}_{2} \mathrm{O}$ elimination. In both dimers, the decreasing $\mathrm{Cu} \cdots \mathrm{Cu}$ distance with increasing pressure continues, reaching 2.914(3) $\AA$ for $\mathrm{Cu} 1-\mathrm{Cu} 1 *$ and 2.849(9) $\AA$ for $\mathrm{Cu} 3-\mathrm{Cu} 4$ at the highest pressure $(2.5 \mathrm{GPa})$ measured.

Complexes 10 and $\mathbf{1 1}$ are less affected by the application of pressure. In 10, the $\mathrm{Cu} \cdots \mathrm{Cu}$ distance decreases from 2.9784(3) $\AA$ at ambient pressure to 2.908(7) $\AA$ at $0.90 \mathrm{GPa}$, with the $\mathrm{Cu}-\mathrm{O}-\mathrm{Cu}$ angles changing from $102.76(6)^{\circ}$ and $101.62(6)^{\circ}$ to $99.3(10)^{\circ}$ and $104.2(11)^{\circ}$. The shortening of the $\mathrm{Cu} \cdots \mathrm{Cu}$ distance is likely due to the contraction of the bond between $\mathrm{Cu} 2$ and the two bridging hydroxide ions decreasing from 1.9198(12) $\AA$ to 1.77(3) $\AA$, thus becoming one of the shortest $\mathrm{Cu}^{\mathrm{II}}-\mathrm{OH}$ distances ever reported. The presence of the two $\mathrm{BF}_{4}{ }^{-}$anions in $\mathbf{1 1}$ results in a more rigid structure, reducing the effect of applying pressure. The $\mathrm{Cu}-\mathrm{F}$ distances decrease from $2.775(2) \AA$ to 2.503 (3) $\AA$ (ambient pressure $\rightarrow 4.7 \mathrm{GPa}$ ), the $\mathrm{Cu} \cdots \mathrm{Cu}$ distance changes from $2.8663(17) \AA$ to $2.8210(19) \AA$, and the $\mathrm{Cu}-\mathrm{O}-\mathrm{Cu}$ angles decrease from $97.40(14)^{\circ}$ at ambient pressure to $95.6(2)^{\circ}$ at $4.7 \mathrm{GPa}$. 
Table 6. Selected distances $(\AA)$ and angles $\left({ }^{\circ}\right)$ in compounds $\mathbf{9 - 1 1}$ as a function of pressure (GPa).

\begin{tabular}{|c|c|c|c|c|c|}
\hline \multirow{2}{*}{$P / G P a$} & \multicolumn{5}{|c|}{9} \\
\hline & $\mathrm{Cu} 1 \cdots \mathrm{Cu} 1^{*}$ & Cu1-O10-Cu1* & Cu1-Cu1*-O11 & & \\
\hline ambient & $2.9784(12)$ & 102.03(13) & $91.41(16)$ & & \\
\hline 0.25 & 2.9578(19) & $101.2(3)$ & $88.7(3)$ & & \\
\hline 0.70 & $2.946(2)$ & 101.1(3) & $87.4(3)$ & & \\
\hline \multirow[t]{2}{*}{1.20} & $2.939(3)$ & $99.7(7)$ & $80.4(7)$ & & \\
\hline & $\mathrm{Cu} 1 \cdots \mathrm{Cu} 2$ & $\mathrm{Cu} 1-\mathrm{O} 1-\mathrm{Cu} 2$ & $\mathrm{Cu} 1-\mathrm{O} 2-\mathrm{Cu} 2$ & $\mathrm{Cu1-Cu2-O5}$ & $\mathrm{Cu} 2-\mathrm{Cu} 1-\mathrm{O} 6$ \\
\hline \multirow[t]{2}{*}{2.50} & $2.914(3)$ & $98.4(4)$ & 99.5(6) & 91.2(4) & $80.1(4)$ \\
\hline & $\mathrm{Cu} 3 \cdots \mathrm{Cu} 4$ & $\mathrm{Cu} 3-\mathrm{O} 3-\mathrm{Cu} 4$ & $\mathrm{Cu} 3-\mathrm{O} 4-\mathrm{Cu} 4$ & $\mathrm{Cu} 3-\mathrm{Cu} 4-\mathrm{O} 7$ & \\
\hline \multirow[t]{3}{*}{2.50} & $2.004(16)$ & $93.9(13)$ & $94.0(7)$ & $67.4(6)$ & \\
\hline & & & 10 & & \\
\hline & $\mathrm{Cu} 1 \cdots \mathrm{Cu} 2$ & Cu1-O1-Cu2 & $\mathrm{Cu} 1-\mathrm{O} 2-\mathrm{Cu} 2$ & & \\
\hline ambient & $2.9784(3)$ & $102.72(6)$ & $101.62(6)$ & & \\
\hline 0.21 & $2.964(3)$ & $103.3(5)$ & $102.4(5)$ & & \\
\hline \multirow[t]{3}{*}{0.90} & $2.908(7)$ & $99.3(10)$ & $104.2(11)$ & & \\
\hline & & & 11 & & \\
\hline & $\mathrm{Cu} 1 \cdots \mathrm{Cu} 1^{*}$ & Cu1-O10 & Cu1-F1 & Cu1-010-Cu1* & \\
\hline ambient & $2.8663(17)$ & $1.908(2)$ & $2.775(2)$ & $97.40(14)$ & \\
\hline 0.30 & $2.8689(17)$ & $1.910(2)$ & $2.768(3)$ & $97.37(17)$ & \\
\hline 0.80 & $2.8649(14)$ & $1.911(2)$ & $2.711(2)$ & $97.13(14)$ & \\
\hline 1.53 & $2.8544(12)$ & $1.9069(19)$ & $2.655(2)$ & $96.91(13)$ & \\
\hline 2.25 & $2.8427(15)$ & $1.908(2)$ & $2.609(3)$ & $96.33(16)$ & \\
\hline 2.80 & $2.8422(12)$ & $1.907(2)$ & $2.577(2)$ & $96.35(14)$ & \\
\hline 3.50 & $2.8331(13)$ & $1.914(2)$ & $2.548(2)$ & $95.49(14)$ & \\
\hline 4.00 & $2.8313(14)$ & $1.913(3)$ & $2.530(3)$ & $95.45(18)$ & \\
\hline 4.30 & $2.8374(17)$ & $1.920(3)$ & $2.543(4)$ & $95.3(2)$ & \\
\hline 4.70 & $2.8210(19)$ & $1.904(3)$ & $2.503(3)$ & $95.6(2)$ & \\
\hline
\end{tabular}

HP dc magnetic susceptibility data $(T=350-20 \mathrm{~K}, B=0.1 \mathrm{~T})$ were collected at ambient pressure to a maximum pressure of $0.84 \mathrm{GPa}(\mathbf{9}), 0.87 \mathrm{GPa}(\mathbf{1 0})$, and $0.86 \mathrm{GPa}(\mathbf{1 1})$ using Daphne oil. Simulation of the susceptibility data at ambient pressure reveals strong antiferromagnetic exchange in 9 and $10\left(J=-260 \mathrm{~cm}^{-1}\right.$ and $J=-252 \mathrm{~cm}^{-1}$, respectively) and moderate ferromagnetic exchange in 11 $\left(J=+22 \mathrm{~cm}^{-1}\right)$. The $\chi_{\mathrm{M}} T$ value for complexes 9 and 10 at low temperatures (up to $90 \mathrm{~K}$ ) are $0 \mathrm{~cm}^{3}$ mol K $\mathrm{K}^{-1}$ at all pressures. As the temperature increases, the $\chi_{\mathrm{M}} T$ value of 9 increases, following different paths as a function of the applied pressure, reaching a maximum value of $0.28 \mathrm{~cm}^{3} \mathrm{~mol}^{-1} \mathrm{~K}$ at ambient pressure and $0.39 \mathrm{~cm}^{3} \mathrm{~mol}^{-1} \mathrm{~K}$ at $0.84 \mathrm{GPa}$. The data follow a similar trend for complex 10 with $\chi_{\mathrm{M}} T$ changing from $0.30 \mathrm{~cm}^{3} \mathrm{~mol}^{-1} \mathrm{~K}$ to $0.34 \mathrm{~cm}^{3} \mathrm{~mol}^{-1} \mathrm{~K}$ (ambient pressure $\rightarrow 0.87 \mathrm{GPa}$ ) at $T=350 \mathrm{~K}$. This behaviour reveals a weakening of the antiferromagnetic interaction between the $\mathrm{Cu}^{\mathrm{II}}$ ions. The parameters obtained from the simulations at different pressures (Table 7) show that $J$ decreases from $-260 \mathrm{~cm}^{-1}$ to $-203 \mathrm{~cm}^{-1}$ for 9 and from $-252 \mathrm{~cm}^{-1}$ to $-228 \mathrm{~cm}^{-1}$ for 10 with increasing pressure, which is in agreement with magneto-structural correlations developed for $\left[\mathrm{Cu}_{2}(\mathrm{OH})_{2}\right]$ dimers in which decreasing $\mathrm{Cu}-\mathrm{O}-\mathrm{Cu}$ angles, $\mathrm{Cu}-\mathrm{O}$, and $\mathrm{Cu} \cdots \mathrm{Cu}$ distances are all expected to decrease $|J|[58]$. HP susceptibility measurements of $\mathbf{1 1}$ show a small increase in the $\chi_{\mathrm{m}} T$ value with increasing pressure, with $J$ increasing from $+22.0 \mathrm{~cm}^{-1}$ at ambient pressure to $+29.4 \mathrm{~cm}^{-1}$ at $0.86 \mathrm{GPa}$. 
Table 7. Comparison of the $J$ values as a function of pressure for complexes $\mathbf{9 - 1 1}$, with $g=2.09$ for 9 and 10, and $g=2.11$ for $\mathbf{1 1}$.

\begin{tabular}{cccccc}
\hline \multicolumn{9}{c}{$\mathbf{9}$} & \multicolumn{3}{c}{$\mathbf{1 0}$} & \multicolumn{2}{c}{$\mathbf{1 1}$} \\
\hline $\boldsymbol{P}(\mathrm{GPa})$ & $\boldsymbol{J}\left(\mathbf{c m}^{\mathbf{- 1}}\right)$ & $\boldsymbol{P}(\mathrm{GPa})$ & $\boldsymbol{J}\left(\mathbf{c m}^{\mathbf{- 1}}\right)$ & $\boldsymbol{P}(\mathbf{G P a})$ & $\boldsymbol{J}\left(\mathbf{c m}^{\mathbf{- 1}}\right)$ \\
\hline ambient & -260 & ambient & -252 & ambient & +22 \\
0.22 & -222 & 0.30 & -246 & 0.40 & +24 \\
0.59 & -220 & 0.58 & -234 & 0.61 & +25.5 \\
0.84 & -203 & 0.87 & -228 & 0.86 & +29.4 \\
\hline
\end{tabular}

Previous HP powder XRD (PXRD) and magnetic susceptibility measurements on the coordination polymer $\left[\mathrm{Cu}^{\mathrm{II}} \mathrm{F}_{2}\left(\mathrm{H}_{2} \mathrm{O}\right)_{2}\right.$ (pyz)] (12, pyz = pyrazine) had shown successive structural phase transitions and a pronounced change in the effective dimensionality of the extended $\mathrm{Cu}^{\mathrm{II}} \ldots \mathrm{Cu}^{\mathrm{II}}$ exchange interactions from 2D to 1D [59]. To further complement this study, we performed detailed HP single-crystal XRD and HP single-crystal electron paramagnetic resonance (EPR) spectroscopy on $\mathbf{1 2}$ in order to provide direct information regarding any pressure-induced reorientation of the JT $\left(d_{z^{2}}\right)$ axes and magnetic $\left(d_{x^{2}-y^{2}}\right)$ orbitals. At ambient pressure, complex 12 crystallises in the monoclinic space group $P 2_{1} / c$ with one $\mathrm{Cu}^{\mathrm{II}}$ ion in the asymmetric unit (Figure 15). The six-coordinate, JT distorted octahedral $\mathrm{Cu}^{\mathrm{II}}$ ion is bonded to two O-atoms (1.984(4) $\AA$ ) from the two $\mathrm{H}_{2} \mathrm{O}$ ligands, two $\mathrm{F}^{-}$ions (1.908(4) $\AA$ ), and two $\mathrm{N}$-atoms (2.454(6) $\AA$ ) from the pyz ligands. The latter define the orientation of the JT axis, whereby the pyz ligands direct the formation of 1D chains along the $a$-axis of the unit cell. In the $b c$ plane, these chains are linked into a 2D network by short $\mathrm{Cu}-\mathrm{OH} \cdots \mathrm{F}-\mathrm{Cu} \mathrm{H}-$ bonds $(2.623(4) \AA$ and $2.607(4)$ $\AA)$. Therefore, the magnetic $d_{x^{2}-y^{2}}$ orbital of the $\mathrm{Cu}^{\mathrm{II}}$ ion lies in the $\mathrm{CuF}_{2} \mathrm{O}_{2}(b c)$ plane, as confirmed by ambient low temperature magnetisation data, which show a $2 \mathrm{D}$ antiferromagnetic magnetic order with $T_{\mathrm{N}}=2.54 \mathrm{~K}$.

a)

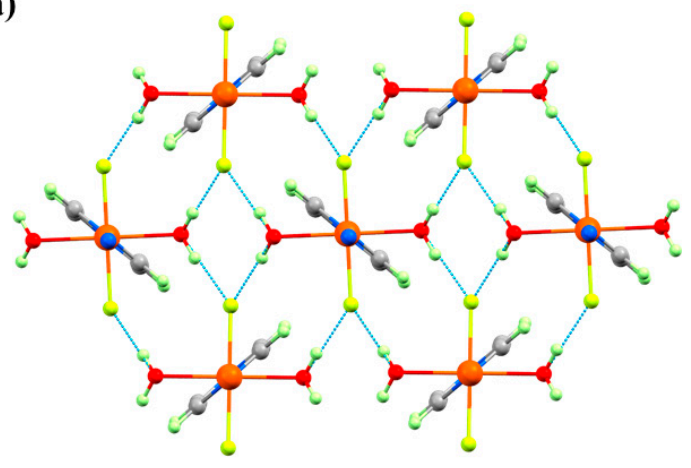

b)

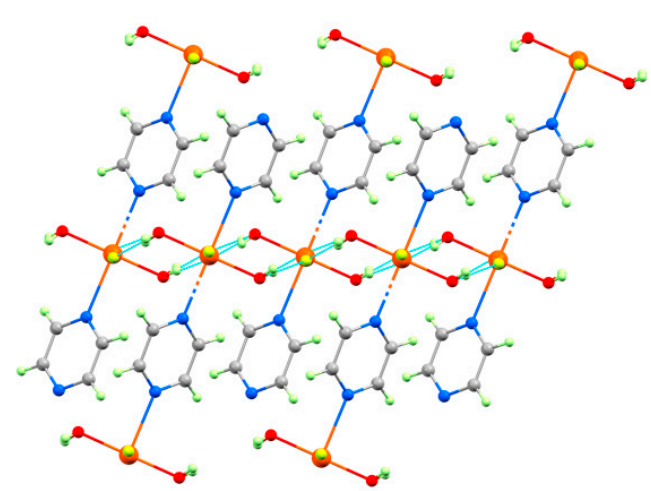

Figure 15. The molecular structure of complex 12 showing (a) the $2 \mathrm{D}$ network in the $b c$-plane, and (b) the $1 \mathrm{D}$ chains directed by the pyz ligands along the $a$-axis. The dashed light blue lines highlight the $\mathrm{Cu}-\mathrm{OH} \cdots \mathrm{F}-\mathrm{Cu} \mathrm{H}$-bonds. Colour code: $\mathrm{Cu}=$ orange, $\mathrm{O}=$ red, $\mathrm{N}=$ blue, $\mathrm{C}=$ grey, $\mathrm{F}=$ yellow, $\mathrm{H}=$ pale green.

HP single-crystal XRD measurements were performed in petroleum ether, with room temperature data collected at 0.50, 0.90, 1.20, 1.80, 2.20, 2.50, 2.85, and 3.30 GPa [60]. The initial effect of pressure is a compression of the unit cell, and while the $\mathrm{Cu}-\mathrm{N}, \mathrm{F}$, and $\mathrm{O}$ distances do not change significantly up to $1.2 \mathrm{GPa}$; both $\mathrm{Cu}-\mathrm{OH} \cdots \mathrm{F}-\mathrm{Cu}$ hydrogen bonds compress to $2.515(13) \AA$. This value is exceptionally short for this type of interaction and hints at a build-up of strain in the $b c$ plane. At $1.8 \mathrm{GPa}$, the phase modification (Phase II) observed in the PXRD measurements occurs. The crystallographic symmetry is maintained, but the $\mathrm{Cu}-\mathrm{N}$ bond lengths decrease by approximately $0.4 \AA$ to 2.039 (3) $\AA$, and the $\mathrm{Cu}-\mathrm{O}$ bonds increase by $0.3 \AA$ to $2.316(3) \AA$. This reflects the reorientation of the JT axis from the $\mathrm{N}-\mathrm{Cu}-\mathrm{N}$ direction to the $\mathrm{O}-\mathrm{Cu}-\mathrm{O}$ direction, and it means the magnetic $d_{x^{2}-y^{2}}$ orbital is now oriented 
along the 1D pyrazine chains. This structural reorganisation simultaneously relieves the tension in the $\mathrm{OH} \cdots \mathrm{F}$ hydrogen bonds, which increase to 2.702(3) and 2.626(3) $\AA$, respectively. 12 undergoes a second, even more disruptive, pressure-induced phase transition between 2.85 and $3.30 \mathrm{GPa}$ to the triclinic space group $P-1$ (Phase IV). During this transition, one $\mathrm{H}_{2} \mathrm{O}$ molecule per $\mathrm{Cu}$ unit from two-thirds of the chains is lost, forcing a dimerisation of the chains through the $\mathrm{F}^{-}$ions (Figure 16). The remaining one-third of the chains are unchanged. Interestingly, and in contrast to 3 where the solvent was ejected from the lattice, the expelled water molecules remain in the crystal lattice and sit between the monomeric and dimeric chains, which are held in place by the $\mathrm{OH} \cdots \mathrm{F}$ H-bonding network. In Phase IV, the JT axes are now oriented along the $\mathrm{O}-\mathrm{Cu}-\mathrm{F}$ bonds $\left(\mathrm{Cu} 2-\mathrm{O} 1,2.22(3) \AA\right.$, $\mathrm{Cu} 2-\mathrm{F}^{*}, 2.28(2)$ $\AA$ ), and adjacent $\mathrm{Cu}$ ions within the dimerised chains are now bridged directly by $\mathrm{F}^{-}$ions (Cu2-F6, 1.908(18) $\left.\AA ; \mathrm{Cu} 2-\mathrm{F} 6-\mathrm{Cu}_{2}^{*}, 103.0(8)^{\circ}\right)$. A separate study has revealed a third transformation route at 3.3 GPa which leads to a phase in which the chemical connectivity and orientation of the JT axes in Phase II were retained but its symmetry is reduced to triclinic, and the orientation of the pyrazine ligands changes [61].
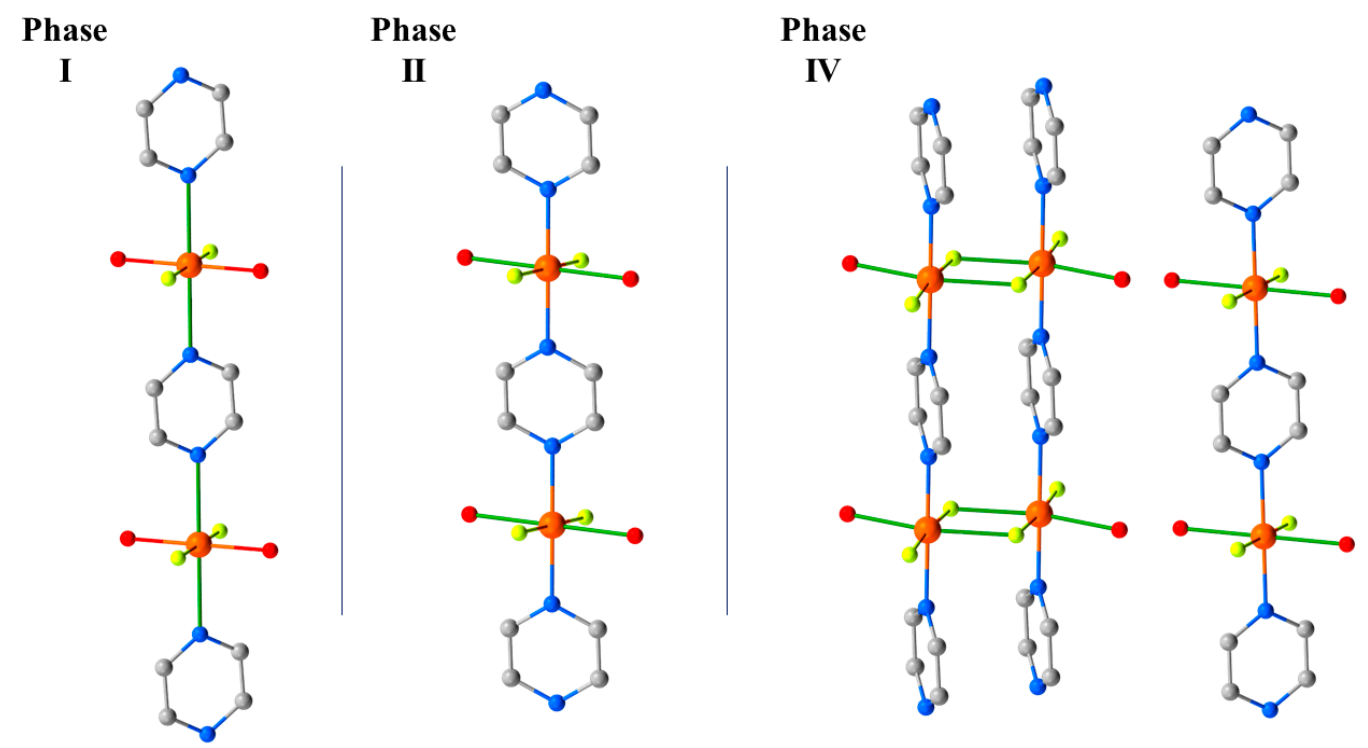

Figure 16. Phases I, II, and IV observed in the HP single-crystal XRD for complex 12. The green bonds highlight the orientation of JT axis $\left(d_{z^{2}}\right)$ of the $\mathrm{Cu}$ iI ion along the $a$-axis of the cell. The magnetic $d_{x^{2}-y^{2}}$ orbital lies perpendicular to this, in the $b c$ plane. Phase III observed in the pXRD measurements [59] was not seen in the single-crystal XRD measurements. Colour code is the same as in Figure 15. H atoms are omitted for clarity.

HP single-crystal EPR measurements at $0.67 \mathrm{GPa}$ (Figure 17) as a function of field orientation at $69.3 \mathrm{GHz}$ and $10 \mathrm{~K}$ show a single, sharp peak with strong angle dependence and $g$-value extrema of $g_{\|}$ $=2.42$ and $g_{\perp}=2.08$. The former corresponds to the direction parallel to the JT axis. At 1.82 GPa and $65.7 \mathrm{GHz}$ two signals are observed, one with a similar angle dependence to the low-pressure signal and a second with a weaker angle dependence and $g$-values in the 2.05-2.10 range. This corresponds to field rotation within the plane of the $d_{x^{2}-y^{2}}$ orbital, i.e., the $\perp$ orientation. Measurements at $96 \mathrm{GHz}$ (Figure 17b) also suggest that part of the sample has transformed to Phase II, i.e., the mechanism of the phase transformation occurs in domains rather than via a concerted transition over the whole crystal; this is local information only visible through spectroscopy and not recognised from the crystallographic data, which yields only an average structure. The strongly angle-dependent signal vanishes completely upon increasing the pressure to $2.1 \mathrm{GPa}$, and the EPR intensity is observed only in a single, broad low $g$-value signal that displays weak angle dependence. This is direct evidence that the magnetic $d_{x^{2}-y^{2}}$ orbital has switched from the $\mathrm{CuF}_{2} \mathrm{O}_{2}$ plane to the $\mathrm{CuF}_{2} \mathrm{~N}_{2}$ plane. Access to the pressure at 
which the second phase transition was observed (i.e., to Phase IV) was beyond the technological capabilities of the plastic EPR cells.
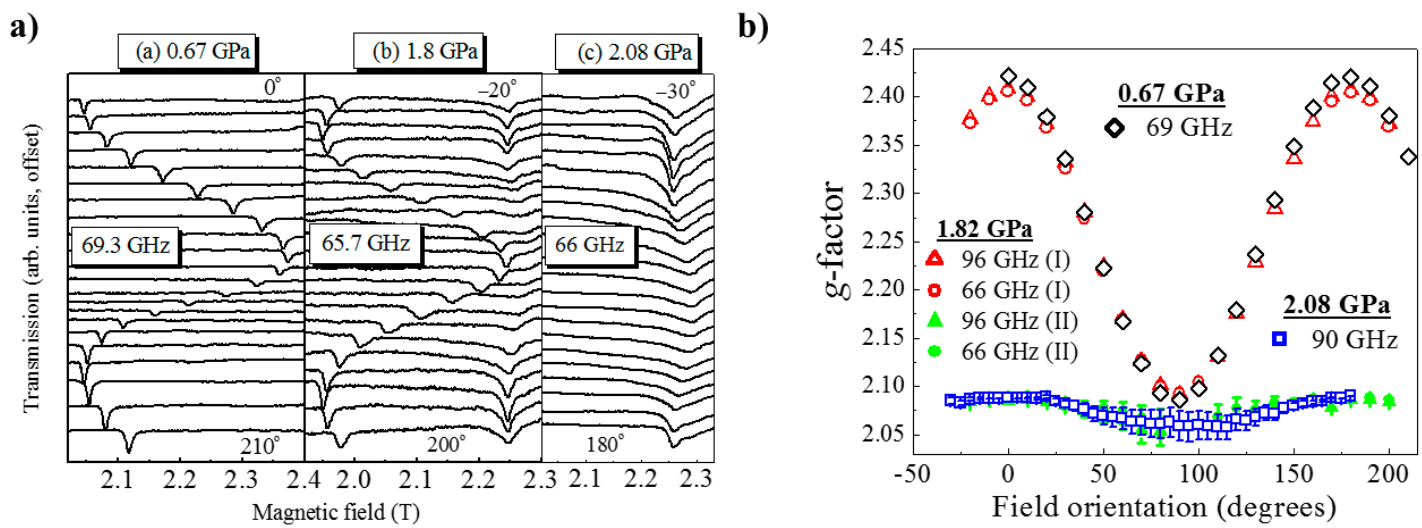

Figure 17. (a) Experimental electron paramagnetic resonance (EPR) spectra recorded at $10 \mathrm{~K}$ as a function of field orientation within the $a b$ plane of a single crystal (transmission offset). The three panels correspond to three different pressures and microwave frequencies. Spectra were recorded every $10^{\circ}$, with $0^{\circ}$ corresponding to the field along the $a$-axis; the field orientations corresponding to the top and bottom traces are indicated in each panel. (b) EPR peak positions taken from (a) together with data obtained at other frequencies (not shown), which are plotted as their corresponding $g$-factors versus the orientation of the applied field within the $a b$ plane of the crystal.

\section{Ni Compounds}

Research in the field of Single-Ion Magnets (SIMs) has focussed on achieving precise control over the coordination geometry of a single paramagnetic (d-/f-block) metal ion in order to construct a specific ligand field that generates first order spin-orbit coupling (SOC) [62-64]. An attractive option for $\mathrm{HP}$ measurements is $\mathrm{Ni}^{\mathrm{II}}$, for which a range of 4-/5-coordinate, air-/moisture-stable species are known. For example, ambient pressure magnetic measurements and HF-EPR studies performed on both oriented single crystals and powder samples of the complex $\left[\mathrm{Ni}(\mathrm{MeDABCO})_{2} \mathrm{Cl}_{3}\right]\left(\mathrm{ClO}_{4}\right)$ (13, MeDABCO = 1-methyl-4-aza-1-azoniabicyclo[2.2.2] octanium) had shown it to possess $|D| \geq 400$ $\mathrm{cm}^{-1}$ [65]. Given that $|D|$ is highly sensitive to changes in coordination geometry, it appeared to be an ideal candidate to explore the effects of pressure. Complex 13 (Figure 18) crystallises in the orthorhombic space group $P c a 2{ }_{1}$. The structure describes a simple 5-coordinate, slightly distorted trigonal prismatic $\mathrm{Ni}^{\mathrm{II}}$ ion bonded to two axial $\mathrm{MeDABCO}^{+}$ligands and three equatorial $\mathrm{Cl}^{-}$ions (Table 8). The structural distortions away from ideal $D_{3 \mathrm{~h}}$ symmetry arise from the JT effect, which splits the degeneracy of the $d_{x z}-d_{y z}$ and $d_{x^{2}-y^{2}}-d_{x y}$ pairs of orbitals [66].

Table 8. Selected distances $(\AA)$ and angles $\left(^{\circ}\right)$ in compound 13 as a function of pressure (GPa).

\begin{tabular}{cccccc}
\hline P/GPa & Ni1-N11 & Ni1-N21 & Ni1-Cl1 & Ni1-Cl2 & Ni1-Cl3 \\
\hline ambient & $2.230(2)$ & $2.215(2)$ & $2.293(1)$ & $2.3016(9)$ & $2.305(1)$ \\
1.65 & $2.199(6)$ & $2.190(6)$ & $2.295(2)$ & $2.298(3)$ & $2.311(2)$ \\
& N11-Ni1-N21 & Cl1-Ni1-Cl2 & Cl2-Ni1-Cl3 & Cl1-Ni1-Cl3 & \\
ambient & $177.1(1)$ & $123.2(1)$ & $119.0(1)$ & $117.7(1)$ & \\
1.65 & $176.2(2)$ & $124.3(1)$ & $123.4(1)$ & $112.3(1)$ & \\
\hline
\end{tabular}


a)

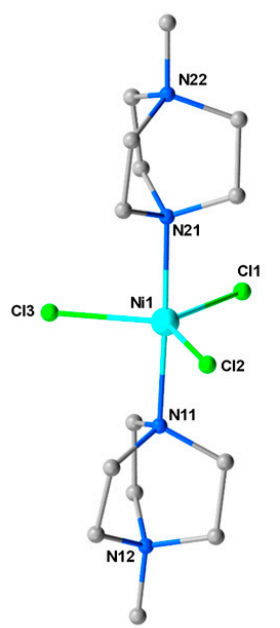

b)

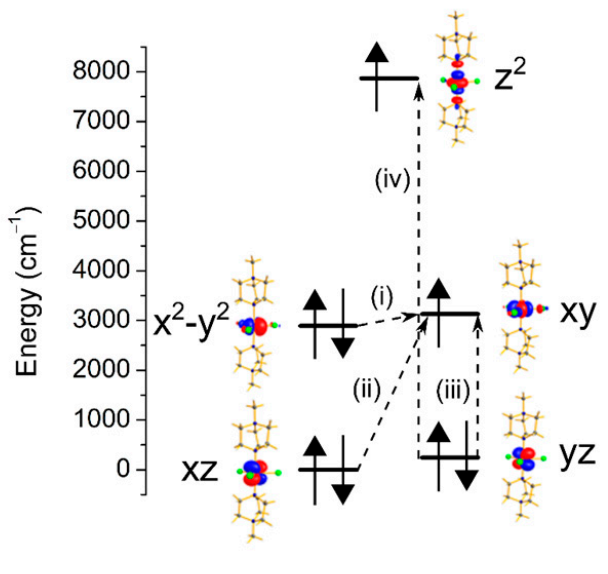

Figure 18. (a) The molecular structure of the cation of 13 . Colour code: $\mathrm{Ni}=$ cyan, $\mathrm{N}=$ blue, $\mathrm{C}=$ grey, $\mathrm{Cl}=$ green. $\mathrm{H}$ atoms and counterions are omitted for clarity. (b) NEVPT2-LFT computed d-orbital energies of the $\mathrm{Ni}^{\mathrm{II}}$ ion at ambient pressure along with the most significant excitations that contribute to the total $D$ value: (i) $-488 \mathrm{~cm}^{-1}$; (ii) $+22 \mathrm{~cm}^{-1}$; (iii) $+19 \mathrm{~cm}^{-1}$; (iv) $+8 \mathrm{~cm}^{-1}$.

HP single-crystal XRD measurements were performed using Fluorinert FC-77 at four different pressures, to a maximum of $1.65 \mathrm{GPa}$; unit cell parameters were determined over the pressure range 0.58-3.51 GPa [67]. 13 remains in the same space group in the full pressure range without major changes in the relative orientation of the molecules in the lattice (the volume decreases from $2145.0(4)$ $\AA^{3}$ at ambient to $1936.4(3) \AA^{3}$ at $1.65 \mathrm{GPa}$ ), and the effect of applying pressure on the bond lengths around the $\mathrm{Ni}^{\mathrm{II}}$ ion is negligible (Table 8). In contrast, there are significant changes to the equatorial bond angles: $\mathrm{Cl1}-\mathrm{Ni1}-\mathrm{Cl} 2$ and $\mathrm{Cl} 2-\mathrm{Ni1}-\mathrm{Cl} 3$ increase to $124.3(1)^{\circ}$ and $123.4(1)^{\circ}$, respectively, while $\mathrm{Cl1}-\mathrm{Ni1}-\mathrm{Cl} 3$ decreases to $112.3(1)^{\circ}$. A small decrease in the trans $\mathrm{N}-\mathrm{Ni}-\mathrm{N}$ angle is also observed $\left(177.1(1) \rightarrow 176.2(2)^{\circ}\right)$. The net result is a further lowering of the symmetry around the metal centre, as confirmed by continuous shape measures, which reveal $S\left(D_{3 \mathrm{~h}}\right)=0.09$ at ambient pressure and $S\left(D_{3 \mathrm{~h}}\right)$ $=0.23$ at $1.65 \mathrm{GPa}[68]$.

$A b$ initio calculations performed on the four structures collected at $0.58,0.90,1.40$, and $1.65 \mathrm{GPa}$ were employed to extract the $z f s$ parameters $(D, E)$ associated with the gradual loss of symmetry (Table 9). At ambient pressure, the computed $D_{\mathrm{ZZ}}$ axis is found to lie along the pseudo- $C_{3}$ axis (the $\mathrm{N}-\mathrm{Ni}-\mathrm{N}$ direction), and the computed $g_{\mathrm{zz}}$ is found to coincide with this axis. The origin of the very large $D$ value is the closely lying $d_{x^{2}-y^{2}}$ and $d_{x y}$ orbitals (their separation is approximately $239 \mathrm{~cm}^{-1}$ ), which contribute $-488 \mathrm{~cm}^{-1}$ to the total $D$ parameter. Significant, but smaller, positive contributions stem from excitations from the $d_{x z}$ and $d_{y z}$ orbitals to the $d_{x y}$ orbital. Calculations on the structure collected at higher pressure suggest a decrease in $D$ by approximately one-third, from $-399 \mathrm{~cm}^{-1} \mathrm{at}$ $0 \mathrm{GPa}$ to $-264 \mathrm{~cm}^{-1}$ at $1.4 \mathrm{GPa}$, highlighting the extreme sensitivity of the magnetic anisotropy to small structural changes in the $\mathrm{Cl}-\mathrm{Ni}-\mathrm{Cl}$ angles (Table 9). Specifically, these changes lead to a larger separation between the $d_{x y}$ and $d_{x^{2}-y^{2}}$ orbitals, which directly correlates with a decrease in the major contribution to $|D|$. This is accompanied by an increase in the rhombic anisotropy, $|E|$, from $0.10 \mathrm{~cm}^{-1}$ at ambient pressure to $0.86 \mathrm{~cm}^{-1}$ at $1.4 \mathrm{GPa}$, which originates from the increased separation between the and $d_{y z}$ orbitals and an increase in the tunnel splitting between the $M_{\mathrm{S}}= \pm 1$ states. Using the $a b$ initio calculations and HF-EPR data as a starting point, simulations of HP dc magnetic susceptibility data $(T=290-2 \mathrm{~K}, B=1 \mathrm{~T}$ ) collected at four different pressure points to a maximum pressure of $1.08 \mathrm{GPa}$ show clear agreement with a decrease in $|D|$ and an increase in $|E|$ with pressure (Table 10). The availability of theoretical methods for the calculation of anisotropy, exchange coupling, and other magnetic parameters, together with elucidation of the orbital interactions that influence them, is a major development in the field of high-pressure coordination chemistry. We anticipate that it will not only enable meaningful conclusions to be drawn from data which can on occasion suffer from 
poor statistics, but, as this and the next study show, it also pinpoints the electronic source of the magneto-structural correlations seen experimentally.

Table 9. NEVPT2 calculated $D$ and $E$ values computed from the high-pressure single-crystal X-ray data along with the most prominent contribution to $D$, the tunnel splitting of the $M_{\mathrm{S}}= \pm 1$ levels, and the $\delta$ value computed for the structure.

\begin{tabular}{|c|c|c|c|c|c|}
\hline$P / G P a$ & $D / \mathrm{cm}^{-1}$ & $E / \mathrm{cm}^{-1}$ & $\begin{array}{l}\text { Contribution from } \\
\text { 1st Excited State } \\
\text { (NEVPT2)/cm }\end{array}$ & $\begin{array}{c}\text { Tunnel } \\
\text { Splitting/(cm }\end{array}$ & $\begin{array}{c}\text { Sum of } \mathrm{Cl}-\mathrm{Ni}-\mathrm{Cl} \\
\text { Angle Deviation, } \delta /^{\circ}\end{array}$ \\
\hline ambient & -399 & 0.104 & -488 & 0.21 & 6.49 \\
\hline 0.58 & -347 & 0.208 & -435 & 0.42 & 7.64 \\
\hline 0.90 & -317 & 0.419 & -403 & 0.84 & 10.44 \\
\hline 1.40 & -264 & 0.861 & -346 & 1.72 & 15.19 \\
\hline 1.65 & -264 & 0.871 & -346 & 1.75 & 15.4 \\
\hline
\end{tabular}

Table 10. Parameters used for the simulation of the magnetic data for complex 13.

\begin{tabular}{cccccc}
\hline P/GPa & $g_{\mathbf{z}}$ & $g_{\mathbf{x}}$ & $g_{\mathbf{y}}$ & $\mathbf{D} / \mathrm{cm}^{\mathbf{- 1}}$ & $\boldsymbol{E} / \mathrm{cm}^{\mathbf{- 1}}$ \\
\hline ambient & 3.36 & 2.05 & 2.05 & -399 & 0.10 \\
0.52 & 3.28 & 2.12 & 2.13 & -349 & 0.22 \\
0.79 & 3.24 & 2.16 & 2.18 & -323 & 0.33 \\
1.08 & 3.20 & 2.20 & 2.22 & -295 & 0.52 \\
\hline
\end{tabular}

\section{Re Compounds}

Our interest in single ions possessing large magneto-anisotropies next led to $\mathrm{Re}^{\mathrm{IV}}$ [69]. The complexes $\left[\operatorname{ReCl}_{4}(\mathrm{MeCN})_{2}\right] \cdot \mathrm{MeCN}(\mathbf{1 4})$ and $\left[\operatorname{ReBr}_{4}(\right.$ bpym) $)\left(\mathbf{1 5}\right.$, bpym $=2,2^{\prime}$-bipyrimidine) (Figure 19) are characterised by large magnetic anisotropies and significant intermolecular magnetic exchange interactions mediated through $\operatorname{Re}-X \cdots X-\operatorname{Re}$ type contacts $(X=$ halogen), resulting in spin canting (the non-collinearity of neighbouring spin centres) and magnetic order at low temperature $\left(T_{\mathrm{C}}(\mathbf{1 4})=6.5 \mathrm{~K}, T_{\mathrm{C}}(\mathbf{1 5})=18.0 \mathrm{~K}\right)[70,71]$. The dipolar exchange pathways arise as a result of the spin density from the $\mathrm{Re}^{\mathrm{IV}}$ ion being significantly delocalised onto the peripheral atoms of the ligand. Intermolecular magnetic exchange interactions can be modified by changing intermolecular distances, i.e., making these distances shorter would be expected to increase the strength of the exchange and increase the ordering temperature, and one way of achieving this is to exert hydrostatic pressure.

a)

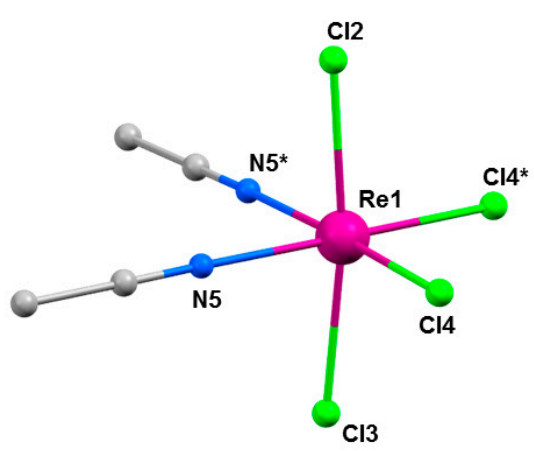

b)

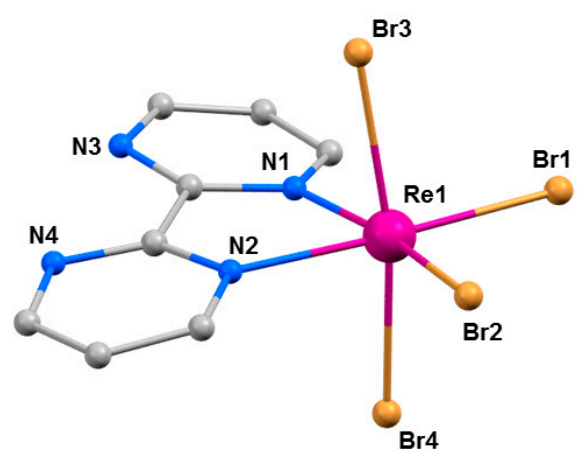

Figure 19. (a) The molecular structure of (a) 14 and (b) 15. Colour code: $R e=$ purple, $N=$ blue, $C=$ grey, $\mathrm{Cl}=$ green, $\mathrm{Br}=$ light brown. $\mathrm{H}$ atoms and solvent molecules are omitted for clarity.

Compounds 14 (Pnma) and $15\left(P 2{ }_{1} 2_{1} 2_{1}\right)$ crystallise in orthorhombic space groups, with the metal ion occupying a distorted octahedral environment, bonded to two $\mathrm{N}$-atoms and four halides. The extended structures display staggered zig-zag chains that propagate along the $a$-axis of the unit cell via interhalide dispersive interactions (Figure 20). Under pressures of up to $4.30 \mathrm{GPa}$, unit cell 
volumes decrease by $20 \%(14)$ and $14 \%$ (15), the principal component of compression occurring down the $c$-axis of the unit cell in both cases [72]. Complex 15 undergoes a phase transition between 1.93 and $3.06 \mathrm{GPa}$ to a monoclinic phase with space group $P 2_{1}$, and when subjected to complete compression-decompression cycles to $4 \mathrm{GPa}$, both complexes return to their original ambient pressure unit cell/space group. In addition, ambient pressure crystal structures solved at $T=4 \mathrm{~K}$ show that both species retain their room temperature structures. The most significant structural changes observed under pressure in $\mathbf{1 4}$ and $\mathbf{1 5}$ occur in the intermolecular Re-X $\cdots$ X-Re distances. For compound 14, the $\mathrm{Re}-\mathrm{Cl} 4 \cdots \mathrm{Cl} 2-\mathrm{Re}$ distance shortens by approximately $0.6 \AA$ to $3.362(11) \AA$, while for compound 15 ,

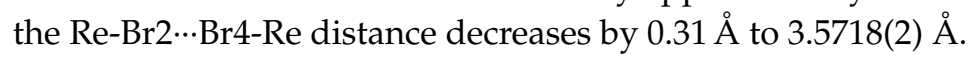

a)

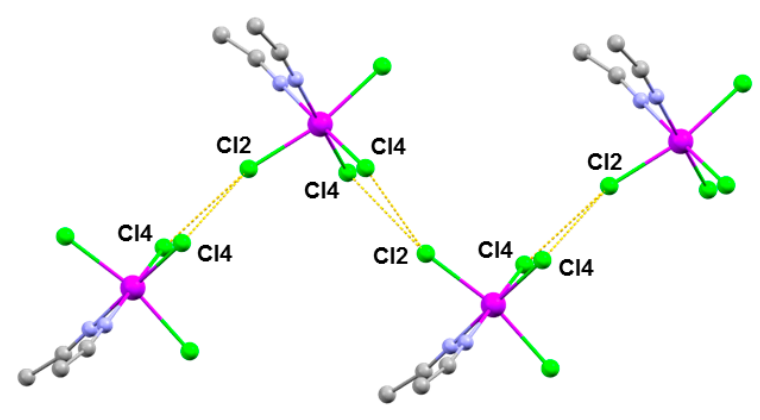

b)

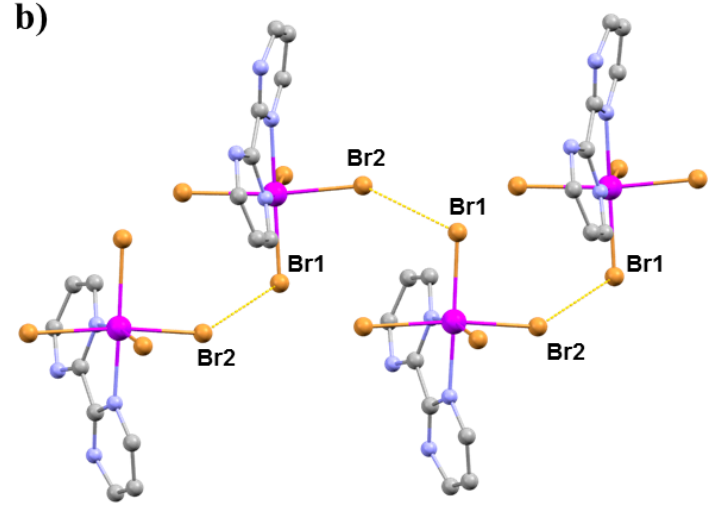

Figure 20. The extended structures of (a) 14 and (b) 15. Colour code: $\mathrm{Re}=$ purple, $\mathrm{N}=$ blue, $\mathrm{C}=$ grey, $\mathrm{Cl}=$ green, $\mathrm{Br}=$ light brown. $\mathrm{H}$ atoms and solvent molecules are omitted for clarity. The dashed lines show the halide $\cdots$ halide interactions.

High-pressure SQUID magnetometry was performed on microcrystalline samples of $\mathbf{1 4}$ and 15 using Daphne oil as the hydrostatic medium. HP dc magnetic measurements $(T=50.0-2.0 \mathrm{~K}$, $B=0.01 \mathrm{~T}$ ) were collected at ambient pressure to a maximum pressure of $4.1 \mathrm{GPa}$ for 14 (4.2 GPa for 15). These experiments show that the application of hydrostatic pressure leads to an increase in ordering temperature (Figure 21). At the highest pressures measured, $T_{\mathrm{C}}$ (determined from field cooled and zero-field cooled measurements as a function of temperature) reaches $28 \mathrm{~K}$ at $4.10 \mathrm{GPa}$ for 14 , and $42 \mathrm{~K}$ at $4.30 \mathrm{GPa}$ for 15. For 14, this represents a four-fold enhancement, with the rate at which $T_{\mathrm{C}}$ increases being 5.1 and $5.4 \mathrm{KGPa}^{-1}$ for $\mathbf{1 4}$ and $\mathbf{1 5}$, respectively. The phase transition observed for compound $\mathbf{1 5}$ does not affect the monotonic increase of the ordering temperature, and in both cases, the changes in $T_{C}$ are reversible; recovery of the ambient pressure $T_{C}$ is observed when the pressure is released from the cell.

a)

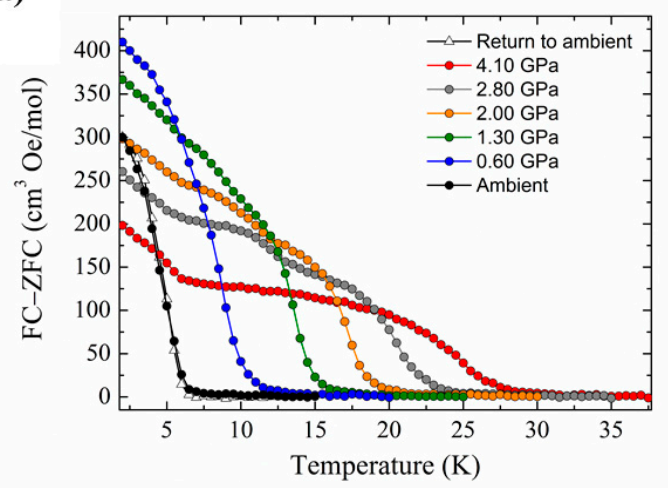

b)

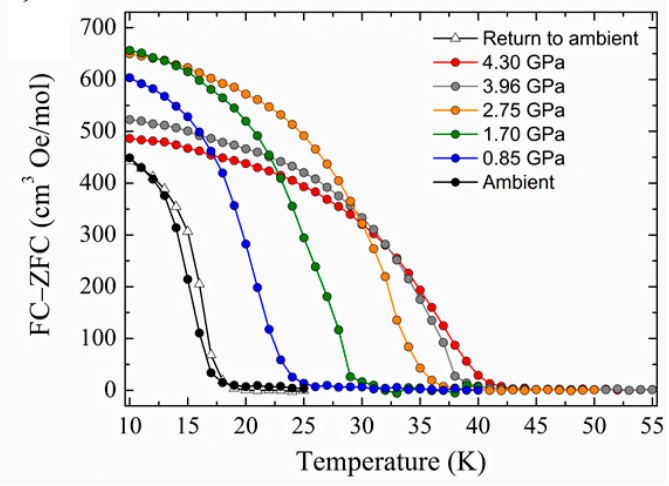

Figure 21. Pressure dependence of the ordering temperature of (a) compound 14 and (b) compound 15. 
Density functional calculations show that the shortest Re-X $\cdots X-$ Re pathways generate the most efficient magnetic exchange interactions at all pressures, and that an increase in the magnitude of $J$ in 14 and 15 is observed when external pressure is applied, which is in agreement with increasing $T_{C}$ in both systems. The correlation between parameters is simple; the external applied pressure produces a linear increase in $J$ and a linear increase in $T_{C}$ (Figure 22).

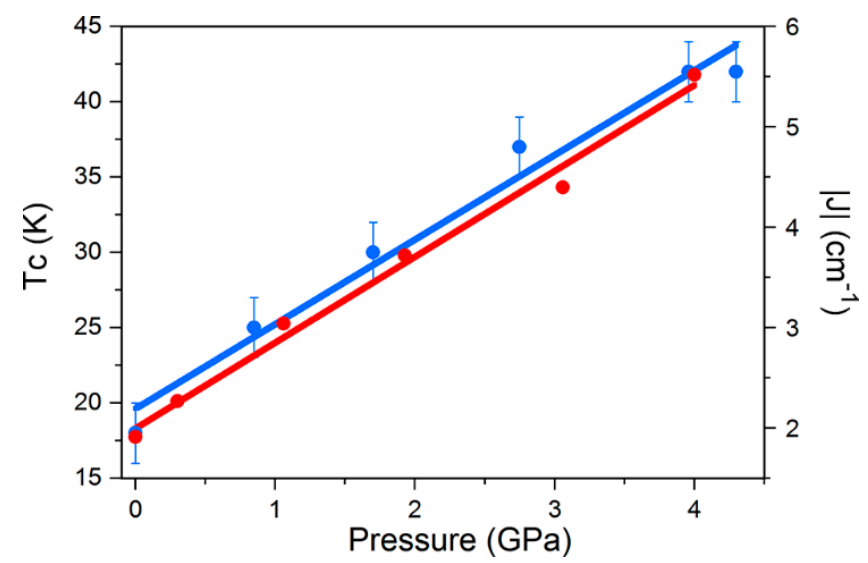

Figure 22. Magneto-structural correlations in 15. The blue circles represent the pressure dependence of the ordering temperature, while the red circles represent the exchange interaction $J$. The lines represent the linear best-fit.

\section{Conclusions}

Despite HP single-crystal XRD being available since the 1950s, reports of its combination with other HP techniques (magnetometry, INS, EPR, absorption/emission/Raman spectroscopy) to examine magneto-structural relationships in molecule-based magnets remain rather rare. This is surprising given the enormous potential benefits on offer. This may be partly due to technology-the design and manufacture of pressure cells for other types of measurements (e.g., magnetometry, EPR) lag behind that of DACs for single-crystal XRD, and these pressure cells often do not reach the same high pressures. Sod's law dictates this is often where the structural changes occur. However, this is not always the case, and as we have summarised above, it is possible to extract a wealth of fascinating and useful information. Looking just at magnetic coordination compounds, we have discovered that pressure can lead to significant changes in bond angles and distances around metal centres, reorientation of JT axes, the breaking and forming of bonds, polymerisation/depolymerisation, multiple phase transitions that can depend on the hydrostatic medium, colour changes, switching of the sign of magnetic exchange interactions $(\mathrm{F} \leftrightarrow \mathrm{AF})$, and enormous changes in zero-field splitting parameters and magnetic ordering temperatures. This is far more than we had first anticipated, and it clearly goes well beyond the removal of voids. This wealth of intramolecular effects distinguishes coordination complexes from purely organic materials, where, except for leading to changes in conformation, the effects of pressure are usually exclusively intermolecular, albeit with some notable exceptions [73]. While it is currently not possible to predict what distortion will occur a priori, it is clear that intermolecular effects are extremely important in determining the sensitivity to pressure of individual bond lengths, angles, and torsions. For example, in a related study on the (non-magnetic) Ni complexes of 6-fluoro and 6-methoxy salicylaldoxime, the $\mathrm{Ni}-\mathrm{O}$ bonds were more sensitive to pressure in the former, and the $\mathrm{Ni}-\mathrm{N}$ bonds were more sensitive in the latter [74]. The effect could be traced to the distribution of interstitial voids formed between the complexes, the less sensitive bonds being oriented toward the voids. In the $\mathrm{Mn}_{12}$ acetate derivative discussed in Section 2, the directions of greatest linear strain lay in the direction of the isomeric Jahn-Teller axis, so that its reorientation can be similarly viewed as being driven by the local intermolecular structure distortion. More research into the role played by intermolecular interactions in the intramolecular pressure response of these materials would be 
very welcome. More generally, high-pressure work requires high quality, mechanically robust crystals. The body of a diamond anvil cell limits the volume of the reciprocal space that can be sampled, and so high symmetry is an advantage. The same effect tends to limit the complexity of refinement models, and so the absence of disorder and relatively low thermal motion are also highly desirable. With ever-improving cell design now making a breadth of characterisation techniques available to HP studies, we hope that this review article highlighting our own work can serve as an example, and as a stimulus, for other researchers to realise that HP techniques may be a valuable addition to their experimental toolkit. One area that we feel will benefit in the short term from combined HP studies is the understanding of the magnetisation relaxation dynamics of SIMs. The latter depend on symmetry, coordination geometry, crystal field, ligand donor strength, and crystal packing. All of these factors are sensitive to pressure, and even small changes to metal geometries can have a profound effect on magnetic anisotropy. Thus, HP structural studies in combination with HP magnetometry, INS, EPR, Raman spectroscopy, and electronic spectroscopy would provide detailed insight into the mechanisms of the relaxation behaviour, including the role of optical and acoustic phonons.

Author Contributions: A.E.-B., S.A.M., M.M. and E.K.B. wrote the manuscript. S.P., K.V.K. and M.R.P. proof-read, reviewed and edited the manuscript. All authors have read and agreed to the published version of the manuscript.

Funding: This research received funding from the EPSRC, grant numbers EP/D503744/1, EP/D503752/1, EP/E06471X/1, EP/H004106/1, EP/K033646/1, EP/K033662/1, EP/K033549/1, EP/N01331X/1. A.E.B. thanks ANID (Chile) for a Postdoctoral Fellowship, grant number 74190043. The work has also benefitted from access to beamtime, initially at the Synchrotron Radiation Source, Daresbury Laboratory, and lately at Diamond Light Source. We are grateful to instrument scientists Simon Teat, John Warren, David Allan and Mark Warren for their extensive help during beamtime.

Acknowledgments: We would like to acknowledge the hard work and dedication of all the PhD students and PDRAs who have worked on these projects, funded on the above-named grants. Alessandro Prescimone, Pascal Parois, Scott McKellar, Javier Sanchez-Benitez, Kyle Galloway, Sergio Sanz, Xiao Wang, Chris Woodall, Jose Martinez-Lillo, Charlie McMonagle, Gavin Craig, Helen Duncan, Angelos Canaj and Marco Coletta.

Conflicts of Interest: The authors declare no conflict of interest.

\section{References}

1. Moggach, S.A.; Parsons, S.; Wood, P.A. High-pressure polymorphism in amino acids. Crystallogr. Rev. 2008, 14, 143-183. [CrossRef]

2. Moggach, S.A.; Parsons, S. High pressure crystallography of inorganic and organometallic complexes. In Spectroscopic Properties of Inorganic and Organometallic Compounds: Techniques, Materials and Applications; Yarwood, J., Douthwaite, R., Duckett, S.B., Eds.; Royal Society of Chemistry: London, UK, 2009; Volume 40, pp. 324-354.

3. McKellar, S.C.; Moggach, S.A. Structural studies of metal-organic frameworks under high pressure. Acta Crystallogr. B 2015, 71, 587-607. [CrossRef] [PubMed]

4. Collings, I.E.; Goodwin, A.L. Metal-organic frameworks under pressure. J. Appl. Phys. 2019, 126, 181101. [CrossRef]

5. Piermarini, G.J.; Mighell, A.D.; Weir, C.E.; Block, S. Crystal Structure of Benzene II at 25 Kilobars. Science 1969, 165, 1250-1255. [CrossRef]

6. Bezzu, C.G.; Burt, L.A.; McMonagle, C.J.; Moggach, S.A.; Kariuki, B.M.; Allan, D.R.; Warren, M.; McKeown, N.B. Highly stable fullerene-based porous molecular crystals with open metal sites. Nat. Mater. 2019, 18, 740-745. [CrossRef] [PubMed]

7. Moggach, S.A.; Allan, D.R.; Parsons, S.; Warren, J.E. Incorporation of a new design of backing seat and anvil in a Merrill-Bassett diamond anvil cell. J. Appl. Crystallogr. 2008, 41, 249-251. [CrossRef]

8. Giriat, G.; Wang, W.; Attfield, J.P.; Huxley, A.D.; Kamenev, K.V. Turnbuckle diamond anvil cell for high-pressure measurements in a superconducting quantum interference device magnetometer. Rev. Sci. Instrum. 2010, 81, 073905. [CrossRef]

9. Binns, J.; Kamenev, K.V.; McIntyre, G.J.; Moggach, S.A.; Parsons, S. Use of a miniature diamond-anvil cell in high-pressure single-crystal neutron Laue diffraction. IUCrJ 2016, 3, 168-179. [CrossRef] 
10. Shirotani, I.; Inagaki, Y.; Utsumi, W.; Yagi, T. Pressure-sensitive absorption spectra of thin films of bis (diphenylglyoximato) platinum (II), Pt (dpg) 2 : Potential application as an indicator of pressure. J. Mater. Chem. 1991, 1, 1041-1043. [CrossRef]

11. Sussardi, A.; Hobday, C.L.; Marshall, R.J.; Forgan, R.S.; Jones, A.C.; Moggach, S.A. Correlating Pressure-Induced Emission Modulation with Linker Rotation in a Photoluminescent MOF. Angew. Chem. Int. Ed. 2020, 59, 8118-8122. [CrossRef]

12. Benjamin, H.; Richardson, J.G.; Moggach, S.A.; Afanasjevs, S.; Warren, L.; Warren, M.R.; Allan, D.R.; Morrison, C.A.; Kamenev, K.V.; Robertson, N. Pressure-induced non-innocence in bis(1,2-dionedioximato) $\mathrm{Pt}$ (II) complexes: An experimental and theoretical study of their insulator-metal transitions. Phys. Chem. Chem. Phys. 2020, 22, 6677-6689. [CrossRef] [PubMed]

13. Madsen, S.R.; Gunnlaugsson, H.P.; Moggach, S.A.; Eikeland, E.; Wu, L.C.; Leupold, O.; Overgaard, J.; Iversen, B.B. X-Ray Diffraction and Mossbauer Spectroscopy Studies of Pressure-Induced Phase Transitions in a Mixed-Valence Trinuclear Iron Complex. Chem. Eur. J. 2016, 22, 9616-9623. [CrossRef]

14. Hobday, C.L.; Marshall, R.J.; Murphie, C.F.; Sotelo, J.; Richards, T.; Allan, D.R.; Duren, T.; Coudert, F.X.; Forgan, R.S.; Morrison, C.A.; et al. A Computational and Experimental Approach Linking Disorder, High-Pressure Behavior, and Mechanical Properties in UiO Frameworks. Angew. Chem. Int. Ed. 2016, 55, 2401-2405. [CrossRef]

15. Thirunavukkuarasu, K.; Winter, S.M.; Beedle, C.C.; Kovalev, A.E.; Oakley, R.T.; Hill, S. Pressure dependence of the exchange anisotropy in an organic ferromagnet. Phys. Rev. B 2015, 91, 014412. [CrossRef]

16. Winter, S.M.; Hill, S.; Oakley, R.T. Magnetic Ordering and Anisotropy in Heavy Atom Radicals. J. Am. Chem. Soc. 2015, 137, 3720-3730. [CrossRef] [PubMed]

17. Guionneau, P.; Collet, E. Piezo-and Photo-Crystallography Applied to Spin-Crossover Materials. In Spin-Crossover Materials: Properties and Applications, 1st ed.; Halcrow, M.A., Ed.; John Wiley \& Sons Ltd.: Oxford, UK, 2013; pp. 507-526.

18. Mito, M.; Deguchi, H.; Tajiri, T.; Takagi, S.; Yamashita, M.; Miyasaka, H. Effect of pressure on single-chain magnets with repeating units of the $\mathrm{Mn}^{\mathrm{III}}-\mathrm{Ni}^{\mathrm{III}}-\mathrm{Mn}^{\mathrm{III}}$ trimer. Phys. Rev. B 2005, 72, 144421. [CrossRef]

19. Awaga, K.; Sekine, T.; Okawa, M.; Fujita, W.; Holmes, S.M.; Girolami, G.S. High-pressure effects on a manganese hexacyanomanganate ferrimagnet with $\mathrm{T}_{\mathrm{N}}=29 \mathrm{~K}$. Chem. Phys. Lett. 1998, 293, 352-356. [CrossRef]

20. Yamashita, M.; Shimizu, H.; Sakoyama, K.; Manabe, T.; Otsuka, T.; Awaga, K. Pressure Effect on Haldane Gap System. Synth. Met. 1999, 103, 2162-2163. [CrossRef]

21. Fujita, W.; Awaga, K. Magnetic Properties of Layered Copper Hydroxides under High Pressure. Mol. Cryst. Liq. Cryst. 2000, 341, 389-393. [CrossRef]

22. Sieber, A.; Chaboussant, G.; Bircher, R.; Boskovic, C.; Güdel, H.U.; Christou, G.; Mutka, H. Pressure dependence of the magnetic anisotropy in the single-molecule magnet $\mathrm{Mn}_{4} \mathrm{O}_{3} \mathrm{Br}(\mathrm{OAc})_{3}(\mathrm{dbm})_{3}$. Phys. Rev . B 2004, 70, 172413. [CrossRef]

23. Tanaka, T.; Fujita, W.; Awaga, K. Pressure effects on magnetic bistability in a heterocyclic thiazyl radical TTTA. Chem. Phys. Lett. 2004, 393, 150-152. [CrossRef]

24. Mito, M.; Fujino, M.; Deguchi, H.; Takagi, S.; Fujita, W.; Awaga, K. Pressure effects on an organic radical ferromagnet $\gamma$-phase BBDTA $\mathrm{GaCl}_{4}$. Polyhedron 2005, 24, 2501-2504. [CrossRef]

25. Kaneko, W.; Mito, M.; Kitagawa, S.; Ohba, M. Interpenetrated Three-Dimensional Mn ${ }^{\mathrm{II}} \mathrm{M}^{\mathrm{III}}$ Ferrimagnets, $\left[\mathrm{Mn}(4 \mathrm{dmap})_{4}\right]_{3}\left[\mathrm{M}(\mathrm{CN})_{6}\right]_{2} \cdot 10 \mathrm{H}_{2} \mathrm{O}(\mathrm{M}=\mathrm{Cr}, \mathrm{Mn})$ : Structures, Magnetic Properties, and Pressure-Responsive Magnetic Modulation. Chem. Eur. J. 2008, 14, 3481-3489. [CrossRef] [PubMed]

26. Ohba, M.; Kaneko, W.; Kitagawa, S.; Maeda, T.; Mito, M. Pressure Response of Three-Dimensional Cyanide-Bridged Bimetallic Magnets. J. Am. Chem. Soc. 2008, 130, 4475-4484. [CrossRef] [PubMed]

27. Rodríguez-Velamazán, J.A.; Fabelo, O.; Beavers, C.M.; Natividad, E.; Evangelisti, M.; Roubeau, O. A Multifunctional Magnetic Material under Pressure. Chem. Eur. J. 2014, 20, 7956-7961. [CrossRef]

28. Peprah, M.K.; VanGennep, D.; Quintero, P.A.; Risset, O.N.; Brinzari, T.V.; Li, C.H.; Dumont, M.F.; Xia, J.S.; Hamlin, J.J.; Talham, D.R.; et al. Pressure-tuning of the photomagnetic response of heterostructured CoFe@CrCr-PBA core@shell nanoparticles. Polyhedron 2017, 123, 323-327. [CrossRef]

29. Gaspar, A.B.; Molnár, G.; Rotaru, A.; Shepherd, H.J. Pressure effect investigations on spin-crossover coordination compounds. Comptes Rendus Chim. 2018, 21, 1095-1120. [CrossRef] 
30. Gütlich, P.; Ksenofontov, V.; Gaspar, A.B. Pressure effect studies on spin crossover systems. Coord. Chem. Rev. 2005, 249, 1811-1829. [CrossRef]

31. Stoleriu, L.; Chakraborty, P.; Hauser, A.; Stancu, C.; Enachescu, C. Thermal hysteresis in spin-crossover compounds studied within the mechanoelastic model and its potential application to nanoparticles. Phys. Rev. B 2011, 84, 134102. [CrossRef]

32. Inglis, R.; Jones, L.F.; Milios, C.J.; Datta, S.; Collins, A.; Parsons, S.; Wernsdorfer, W.; Hill, S.; Perlepes, S.P.; Piligkos, S.; et al. Attempting to understand (and control) the relationship between structure and magnetism in an extended family of $\mathrm{Mn}_{6}$ single-molecule magnets. Dalton Trans. 2009, 18, 3403-3412. [CrossRef]

33. Milios, C.J.; Piligkos, S.; Brechin, E.K. Ground state spin-switching via targeted structural distortion: Twisted single-molecule magnets from derivatised salicylaldoximes. Dalton Trans. 2008, 14, 1809-1817. [CrossRef] [PubMed]

34. Abragam, A.; Pryce, M.H.L. Theoretical Interpretation of Copper Fluosilicate Spectrum. Proc. Phys. Soc. 1950, A63, 409. [CrossRef]

35. Milios, C.J.; Vinslava, A.; Wood, P.A.; Parsons, S.; Wernsodrfer, W.; Christou, G.; Perlepes, S.P.; Brechin, E.K. A Single-Molecule Magnet with a "Twist". J. Am. Chem. Soc. 2007, 129, 8-9. [CrossRef] [PubMed]

36. Milios, C.J.; Vinslava, A.; Moggach, S.; Parsons, S.; Wernsdorfer, W.; Christou, G.; Perlepes, S.P.; Brechin, E.K. A Record Anistropy Barrier for a Single-Molecule Magnet. J. Am. Chem. Soc. 2007, 129, 2754-2755. [CrossRef] [PubMed]

37. Milios, C.J.; Vinslava, A.; Wernsdorfer, W.; Prescimone, A.; Wood, P.A.; Parsons, S.; Perlepes, S.P.; Christou, G.; Brechin, E.K. Spin Switching via Targeted Structural Distortion. J. Am. Chem. Soc. 2007, 129, 6547-6561. [CrossRef]

38. Piligkos, S.; Bendix, J.; Weihe, H.; Milios, C.J.; Brechin, E.K. A ligand-field study of the ground spin-state magnetic anisotropy in a family of hexanuclear Mn (III) single-molecule magnets. Dalton Trans. 2008, 17, 2277-2284. [CrossRef]

39. Milios, C.J.; Inglis, R.; Vinslava, A.; Bagai, R.; Wernsdorfer, W.; Parsons, S.; Perlepes, S.P.; Christou, G.; Brechin, E.K. Toward a Magnetostructural Correlation for a Family of $\mathrm{Mn}_{6}$ SMMs. J. Am. Chem. Soc. 2007, 129, 12505-12511. [CrossRef]

40. Prescimone, A.; Milios, C.J.; Moggach, S.; Warren, J.E.; Lennie, A.R.; Sanchez-Benitez, J.; Kamenev, K.; Bircher, R.; Murrie, M.; Parsons, S.; et al. [ $\left.\mathrm{Mn}_{6}\right]$ under Pressure: A Combined Crystallographic and Magnetic Study. Angew. Chem. Int. Ed. 2008, 47, 2828-2831. [CrossRef]

41. Jones, L.F.; Cochrane, M.E.; Koivisto, B.D.; Leigh, D.A.; Perlepes, S.P.; Wernsdorfer, W.; Brechin, E.K. Tuning magnetic properties using targeted structural distortion: New additions to a family of $\mathrm{Mn}_{6}$ single-molecule magnets. Inorg. Chim. Acta 2008, 361, 3420-3426. [CrossRef]

42. Scott, R.T.W.; Parsons, S.; Murugesu, M.; Wernsdorfer, W.; Christou, C.; Brechin, E.K. Synthesis, structure and magnetic properties of a trinuclear $\left[\mathrm{Mn}^{\mathrm{III}} \mathrm{Mn}_{2}{ }_{2}\right]$ single-molecule magnet. Chem. Commun. 2005, 16, 2083-2085. [CrossRef]

43. Prescimone, A.; Wolowska, J.; Rajaraman, G.; Parsons, S.; Wernsdorfer, W.; Murugesu, M.; Christou, G.; Piligkos, S.; McInnes, E.J.L.; Brechin, E.K. Studies of a linear single-molecule magnet. Dalton Trans. 2007, 45, 5282-5289. [CrossRef] [PubMed]

44. Prescimone, A.; Sanchez-Benitez, J.; Kamenev, K.V.; Moggach, S.A.; Lennie, A.R.; Warren, J.E.; Murrie, M.; Parsons, S.; Brechin, E.K. High pressure effects on a trimetallic Mn ${ }^{\mathrm{II} / \mathrm{III}}$ SMM. Dalton Trans. 2009, 36, 7390-7395. [CrossRef] [PubMed]

45. Soler, M.; Wernsdorfer, W.; Sun, Z.; Huffman, J.C.; Hendrickson, D.N.; Christou, G. Single-molecule magnets: Control by a single solvent molecule of Jahn-Teller isomerism in $\left[\mathrm{Mn}_{12} \mathrm{O}_{12}\left(\mathrm{O}_{2} \mathrm{CCH}_{2} \mathrm{Bu}^{\mathrm{t}}\right)_{16}\left(\mathrm{H}_{2} \mathrm{O}\right)_{4}\right]$. Chem. Commun. 2003, 21, 2672-2673. [CrossRef] [PubMed]

46. Sun, Z.; Ruiz, D.; Hendrickson, D.N.; Dilley, N.R.; Maple, M.B.; Soler, M.; Folting, K.; Christou, G.; Ribas, J. The origin of the second relaxation process in the $\left[\mathrm{Mn}_{12} \mathrm{O}_{12}\left(\mathrm{O}_{2} \mathrm{CR}\right)_{16}\left(\mathrm{H}_{2} \mathrm{O}\right)_{4}\right]$ single-molecule magnets: 'Jahn-Teller isomerism' in the $\left[\mathrm{Mn}_{12} \mathrm{O}_{12}\right.$ ] core. Chem. Commun. 1999, 19, 1973-1974. [CrossRef]

47. Bagai, R.; Christou, G. The Drosophila of single-molecule magnetism: $\left[\mathrm{Mn}_{12} \mathrm{O}_{12}\left(\mathrm{O}_{2} \mathrm{CR}\right)_{16}\left(\mathrm{H}_{2} \mathrm{O}\right)_{4}\right]$. Chem. Soc. Rev. 2009, 38, 1011-1026. [CrossRef] [PubMed]

48. Levchenko, G.G.; Zubov, E.E.; Varyukhin, V.N.; Gaspar, A.B.; Real, J.A. Quantum Tunneling of Magnetization under Pressure in the High-Spin $\mathrm{Mn}_{12}$ Molecular System. J. Phys. Chem. B 2004, 108, 16664-16669. [CrossRef] 
49. Suzuki, Y.; Takeda, K.; Awaga, K. Enhancement of Jahn-Teller isomerism in $\mathrm{Mn}_{12}$ Ac under high quasi-hydrostatic pressure. Phys. Rev. B 2003, 67, 132402. [CrossRef]

50. Sieber, A.; Bircher, R.; Waldmann, O.; Carver, G.; Chaboussant, G.; Mutka, H.; Gudel, H.U. Effect of Pressure on the Magnetic Anisotropy in the Single-Molecule Magnet $\mathrm{Mn}_{12}$-Acetate: An Inelastic Neutron Scattering Study. Angew. Chem. Int. Ed. 2005, 44, 4239-4242. [CrossRef]

51. Parois, P.; Moggach, S.A.; Sanchez-Benitez, J.; Kamenev, K.V.; Lennie, A.R.; Warren, J.E.; Brechin, E.K.; Parsons, S.; Murrie, M. Pressure-induced Jahn-Teller switching in a $\mathrm{Mn}_{12}$ nanomagnet. Chem. Commun. 2010, 46, 1881-1883. [CrossRef]

52. Plaksin, P.M.; Stoufer, R.C.; Mathew, M.; Palenik, G.J. Novel antiferromagnetic oxo-bridged manganese complex. J. Am. Chem. Soc. 1972, 94, 2121-2122. [CrossRef]

53. Prescimone, A.; Sanchez-Benitez, J.; Kamenev, K.V.; Warren, J.E.; Lennie, A.R.; Murrie, M.; Parsons, S.; Brechin, E.K. High-Pressure Study of Oxo-bridged Mixed-Valent $\mathrm{Mn}^{\mathrm{III}} / \mathrm{Mn}^{\mathrm{IV}}$ Dimers. Z. Nat. B 2010, 65, 221-230.

54. Moggach, S.A.; Galloway, K.W.; Lennie, A.R.; Parois, P.; Rowantree, N.; Brechin, E.K.; Warren, J.E.; Murrie, M.; Parsons, S. Polymerisation of a Cu (II) dimer into 1D chains using high pressure. CrystEngComm 2009, 11, 2601-2604. [CrossRef]

55. Galloway, K.W.; Moggach, S.A.; Parois, P.; Lennie, A.R.; Warren, J.E.; Brechin, E.K.; Peacock, R.D.; Valiente, R.; González, J.; Rodríguez, F.; et al. Pressure-induced switching in a Cu (II) citrate dimer. CrystEngComm 2010, 12, 2516-2519. [CrossRef]

56. Crawford, V.H.; Richardson, H.W.; Wasson, J.R.; Hodgson, D.J.; Hatfield, W.E. Relation between the singlet-triplet splitting and the copper-oxygen-copper bridge angle in hydroxo-bridged copper dimers. Inorg. Chem. 1976, 15, 2107-2110. [CrossRef]

57. Prescimone, A.; Sanchez-Benitez, J.; Kamenev, K.K.; Moggach, S.A.; Warren, J.E.; Lennie, A.R.; Murrie, M.; Parsons, S.; Brechin, E.K. High pressure studies of hydroxo-bridged Cu (II) dimers. Dalton Trans. 2010, 39, 113-123. [CrossRef] [PubMed]

58. Ruiz, E.; Alemany, P.; Alvarez, S.; Cano, J. Structural Modeling and Magneto-Structural Correlations for Hydroxo-Bridged Copper (II) Binuclear Complexes. Inorg. Chem. 1997, 36, 3683-3688. [CrossRef]

59. Halder, G.J.; Chapman, K.W.; Schlueter, J.A.; Manson, J.L. Pressure-Induced Sequential Orbital Reorientation in a Magnetic Framework Material. Angew. Chem. Int. Ed. 2011, 50, 419-421. [CrossRef]

60. Prescimone, A.; Morien, C.; Allan, D.; Schlueter, J.A.; Tozer, S.W.; Manson, J.L.; Parsons, S.; Brechin, E.K.; Hill, S. Pressure-Driven Orbital Reorientations and Coordination-Sphere Reconstructions in $\left[\mathrm{CuF}_{2}\left(\mathrm{H}_{2} \mathrm{O}\right)_{2}(\mathrm{pyz})\right]$. Angew. Chem. Int. Ed. 2012, 51, 7490-7494. [CrossRef]

61. Lanza, A.; Fiolka, C.; Fisch, M.; Casati, N.; Skoulatos, M.; Rüegg, C.; Krämera, K.W.; Macchi, P. New magnetic frameworks of $\left[\left(\mathrm{CuF}_{2}\left(\mathrm{H}_{2} \mathrm{O}\right)_{2}\right)_{x}\right.$ (pyz)]. Chem. Commun. 2014, 50, 14504-14507. [CrossRef]

62. Craig, G.A.; Murrie, M. 3d single-ion magnets. Chem. Soc. Rev. 2015, 44, 2135-2147. [CrossRef]

63. Frost, J.M.; Harriman, K.L.M.; Murugesu, M. The rise of 3-d single-ion magnets in molecular magnetism: Towards materials from molecules? Chem. Sci. 2016, 7, 2470-2491. [CrossRef]

64. McAdams, S.G.; Ariciu, A.M.; Kostopoulos, A.K.; Walsh, J.P.S.; Tuna, F. Molecular single-ion magnets based on lanthanides and actinides: Design considerations and new advances in the context of quantum technologies. Coord. Chem. Rev. 2017, 346, 216-239. [CrossRef]

65. Marriott, K.E.R.; Bhaskaran, L.; Wilson, C.; Medarde, M.; Ochsenbein, S.T.; Hill, S.; Murrie, M. Pushing the limits of magnetic anisotropy in trigonal bipyramidal Ni (II). Chem. Sci. 2015, 6, 6823-6828. [CrossRef] [PubMed]

66. Gruden-Pavlović, M.; Perić, M.; Zlatar, M.; García-Fernández, P. Theoretical study of the magnetic anisotropy and magnetic tunnelling in mononuclear Ni (II) complexes with potential molecular magnet behavior. Chem. Sci. 2014, 5, 1453-1462. [CrossRef]

67. Craig, G.A.; Sarkar, A.; Woodall, C.H.; Hay, M.A.; Marriott, K.E.R.; Kamenev, K.V.; Moggach, S.A.; Brechin, E.K.; Parsons, S.; Rajaraman, G.; et al. Probing the origin of the giant magnetic anisotropy in trigonal bipyramidal Ni(II) under high pressure. Chem. Sci. 2018, 9, 1551-1559. [CrossRef] [PubMed]

68. Pinsky, M.; Avnir, D. Continuous Symmetry Measures. 5. The Classical Polyhedra. Inorg. Chem. 1998, 37, 5575-5582. [CrossRef] [PubMed] 
69. Martínez-Lillo, J.; Faus, J.; Lloret, F.; Julve, M. Towards multifunctional magnetic systems through molecular-programmed self assembly of Re (IV) metalloligands. Coord. Chem. Rev. 2015, 289-290, 215-237.

70. Kunz, P.C.; Kurz, P.; Spingler, B.; Alberto, R. Attempted Abstraction of the Halogenides in $\left(\mathrm{HNEt}_{3}\right)\left[\mathrm{Re}\left(\mathrm{CH}_{3} \mathrm{CN}\right)_{2} \mathrm{Cl}_{4}\right]$ and crystal structures of cis- $\left[\operatorname{Re}\left(\mathrm{CH}_{3} \mathrm{CN}\right)_{2} \mathrm{Cl}_{4}\right] \cdot \mathrm{CH}_{3} \mathrm{CN}$ and cis-[Re(NHC(OCH$\left.\left.)_{3} \mathrm{CH}_{3}\right)_{2} \mathrm{Cl}_{4}\right]$. Z. Anorg. Allg. Chem. 2007, 633, 2753-2756. [CrossRef]

71. Martínez-Lillo, J.; Lloret, F.; Julve, M.; Faus, J. Spin canting in Re (IV) complexes: Magnetic properties of $\left[\operatorname{ReX}_{4}(\right.$ bpym $\left.)\right](X=C l$ and Br; bpym=2,2'-bipyrimidine). J. Coord. Chem. 2009, 62, 92-99. [CrossRef]

72. Woodall, C.H.; Craig, G.A.; Prescimone, A.; Misek, M.; Cano, J.; Faus, J.; Probert, M.R.; Parsons, S.; Moggach, S.; Martínez-Lillo, J.; et al. Pressure induced enhancement of the magnetic ordering temperature in rhenium(IV) monomers. Nat. Commun. 2016, 7, 13870. [CrossRef]

73. Casati, N.; Kleppe, A.; Jephcoat, A.P.; Macchi, P. Putting pressure on aromaticity along with in situ experimental electron density of a molecular crystal. Nat. Commun. 2016, 7, 10901. [CrossRef] [PubMed]

74. Byrne, P.J.; Richardson, P.J.; Chang, J.; Kusmartseva, A.F.; Allan, D.R.; Jones, A.C.; Kamenev, K.V.; Tasker, P.A.; Parsons, S. Piezochromism in Nickel Salicylaldoximato Complexes: Tuning Crystal-Field Splitting with High Pressure. Chem. Eur. J. 2012, 18, 7738-7748. [CrossRef] [PubMed]

(C) 2020 by the authors. Licensee MDPI, Basel, Switzerland. This article is an open access article distributed under the terms and conditions of the Creative Commons Attribution (CC BY) license (http://creativecommons.org/licenses/by/4.0/). 